\title{
Hydration of gas-phase ytterbium ion complexes studied by experiment and theory
}

\author{
Philip X. Rutkowski • Maria C. Michelini • \\ Travis H. Bray $\cdot$ Nino Russo $\cdot$ Joaquim Marçalo • \\ John K. Gibson
}

Received: 15 October 2010/Accepted: 28 January 2011/Published online: 16 February 2011

(C) The Author(s) 2011. This article is published with open access at Springerlink.com

\begin{abstract}
Hydration of ytterbium (III) halide/hydroxide ions produced by electrospray ionization was studied in a quadrupole ion trap mass spectrometer and by density functional theory (DFT). Gas-phase $\mathrm{YbX}_{2}{ }^{+}$and $\mathrm{YbX}(\mathrm{OH})^{+}$ $(\mathrm{X}=\mathrm{OH}, \mathrm{Cl}, \mathrm{Br}$, or I) were found to coordinate from one to four water molecules, depending on the ion residence time in the trap. From the time dependence of the hydration steps, relative reaction rates were obtained. It was determined that the second hydration was faster than both the first and third hydrations, and the fourth hydration was the slowest; this ordering reflects a combination of insufficient degrees of freedom for cooling the hot monohydrate ion and decreasing binding energies with increasing hydration number. Hydration energetics and hydrate structures were computed using two approaches of DFT. The relativistic scalar ZORA approach was used with the PBE functional and all-electron TZ2P basis sets; the B3LYP functional
\end{abstract}

Dedicated to Professor Pekka Pyykkö on the occasion of his 70th birthday and published as part of the Pyykkö Festschrift Issue.

Electronic supplementary material The online version of this article (doi:10.1007/s00214-011-0900-5) contains supplementary material, which is available to authorized users.

P. X. Rutkowski · T. H. Bray · J. K. Gibson ( $\square)$ Chemical Sciences Division, Lawrence Berkeley National Laboratory, Berkeley, CA 94720, USA

e-mail: JKGibson@lbl.gov

M. C. Michelini $(\varangle) \cdot$ N. Russo

Dipartimento di Chimica, Università della Calabria,

Via P. Bucci, Cubo 14 C, 87030 Arcavacata di Rende, Italy

e-mail:mc.michelini@unical.it

J. Marçalo

Unidade de Ciências Químicas e Radiofarmacêuticas,

Instituto Tecnológico e Nuclear, 2686-953 Sacavém, Portugal was used with the Stuttgart relativistic small-core ANO/ ECP basis sets. The parallel experimental and computational results illuminate fundamental aspects of hydration of f-element ion complexes. The experimental observations-kinetics and extent of hydration-are discussed in relationship to the computed structures and energetics of the hydrates. The absence of pentahydrates is in accord with the DFT results, which indicate that the lowest energy structures have the fifth water molecule in the second shell.

Keywords Density functional theory · Hydration . Lanthanides · Ytterbium halides · Gas-phase reactions . Kinetics

\section{Introduction}

The hydration of trivalent lanthanide cations and complexes in the condensed phase has been studied extensively. Experimentally, numerous studies have shown that the contraction of the lanthanide ionic radius across the series influences the number of water molecules coordinated to the bare trivalent cations. Most investigations report that, in aqueous solutions of lanthanide trihalides, the bare metal cations, $\mathrm{Ln}^{3+}$, bond exclusively with water molecules and that halide anions are not in the first coordination sphere [1-7]. However, other studies have shown that direct metal-halide coordination can occur by altering the solution conditions. Steele and Wertz have demonstrated, using X-ray diffraction measurements, that $\mathrm{GdCl}_{2}\left(\mathrm{H}_{2} \mathrm{O}\right)_{6}^{+}$is an abundant complex in $10 \mathrm{~N} \mathrm{HCl}$ solutions, whereas in more dilute aqueous solutions, the dominant species is $\mathrm{Gd}\left(\mathrm{H}_{2} \mathrm{O}\right)_{8}^{+}$[8]. In a similar study, these authors reported that $\mathrm{NdCl}_{2}\left(\mathrm{H}_{2} \mathrm{O}\right)_{6}^{+}$is an abundant species in a solution of $\mathrm{NdCl}_{3}$ dissolved in (wet) methanol [9]. 
Using X-ray diffraction, Johansson and Yokoyama have shown that $\mathrm{Cl}^{-}$and $\mathrm{Br}^{-}$anions can enter the first coordination sphere of trivalent $\mathrm{Er}$ only in aqueous $\mathrm{ErCl}_{3}$ and $\mathrm{ErBr}_{3}$ solutions with high concentrations of the anion [10].

Many theoretical studies have examined hydration and coordination of lanthanide ions. A number of these studies applied molecular dynamics simulations of trivalent lanthanides in solution to understand the hydration of the bare metal cation [11-15]. Other studies focused on modeling trivalent lanthanide hydrates in the gas phase. A recent study by Kuta and Clark used DFT calculations to generate structures of the lanthanide hydrates with fully hydrated first and second coordination spheres for the entire series [16]. Similar work has been done on gas-phase trivalent La [17] and Ce [18]. Another study by Clavaguéra et al. modeled lanthanide trihalides and ion complexes [19].

Knowledge of the nature of hydration of bare lanthanide ions and lanthanide complexes is necessary to understand geochemical processes. The solubility of lanthanides in brine solutions is especially important because the rare earth elements can be used as indicators to determine the mechanisms of hydrothermal ore deposition [20]. Geochemical studies focus on temperature and pressure as a function of lanthanide halide solution speciation. A majority of these studies have concentrated on chloride-containing solutions, with only a few on fluoride solution speciation [21]. A study on dilute $\left(\sim 10^{-2} \mathrm{M}\right)$ ytterbium (III) chloride solutions by Mayanovic et al. showed that under high pressure and temperature $\left(500{ }^{\circ} \mathrm{C}\right.$ and $\left.270 \mathrm{MPa}\right), \mathrm{YbCl}_{2}{ }^{+} \cdot\left(\mathrm{H}_{2} \mathrm{O}\right)_{5}$ is the predominant species [22]. Using $\mathrm{X}$-ray absorption fine structure spectroscopy (XAFS), they determined that all five water molecules were directly coordinated to the $\mathrm{Yb}$ metal center. Mayanovic et al. reported similar studies for trivalent $\mathrm{Gd}$ [23] and $\mathrm{Nd}$ [24] and found additional coordinated water molecules at high pressures and temperatures for the dichloride species: $\mathrm{GdCl}_{2}{ }^{+} \cdot\left(\mathrm{H}_{2} \mathrm{O}\right)_{6}$ and $\mathrm{NdCl}_{2}{ }^{+} \cdot\left(\mathrm{H}_{2} \mathrm{O}\right)_{7}$, respectively. Similarly, XAFS showed that all water molecules - remarkably up to seven in the latter case-were directly coordinated to the metal center. The decrease in terminal inner-sphere hydration, from seven for $\mathrm{NdCl}_{2}{ }^{+}$to five for $\mathrm{YbCl}_{2}{ }^{+}$, can be attributed to the lanthanide contraction, which results in a decrease in the effective metal ion radius across the series.

We report on the sequential hydration of trivalent biligated ytterbium dihalide, halide hydroxide, and dihydroxide cations in the gas phase. A primary goal is to further understand the hydration of metal ion complexes, particularly of f-element metals, at a fundamental level by coupling experimental and theoretical studies of gas-phase hydration. Electrospray ionization (ESI) was employed with quadrupole ion trap mass spectrometry (QIT-MS) to examine hydrated ions transferred from solution to the gas phase, as well as the relative kinetics of ion hydration in the gas phase. Of particular interest is the maximum degree of hydration that could be achieved in the gas phase under the most extreme accessible experimental conditions. Gasphase hydrolysis was also observed. To understand the observed hydration behavior of these ions, computational methods were employed. The structures and energetics of the hydrates were computed, and these results are compared with the experimental observations.

Ytterbium is a representative late lanthanide that exhibits a complex and distinctive isotopic pattern, allowing for definitive identification of $\mathrm{Yb}$-containing species in mass spectra. A disadvantage of this isotopic complexity is that certain species cannot be effectively studied due to isobaric interferences; some studies were performed using the mono-isotopic neighboring lanthanide, Tm, which hydrates similarly to trivalent $\mathrm{Yb}$. No experiments were performed on $\mathrm{YbF}_{2}{ }^{+}$or $\mathrm{YbF}(\mathrm{OH})^{+}$due to the insolubility of $\mathrm{YbF}_{3}$ in ESI solvents. Theoretical calculations were carried out on $\mathrm{YbX}_{2}{ }^{+}$and $\mathrm{YbX}(\mathrm{OH})^{+}(\mathrm{X}=\mathrm{OH}, \mathrm{F}, \mathrm{Cl})$ and their hydrates. A direct comparison between experiment and theory is possible for the chloride- and hydroxidecontaining complexes; comparisons are extrapolated between computations and experiments for the bromide and iodide species.

\section{Experimental section}

\subsection{Materials}

Solid $\mathrm{YbCl}_{3} \cdot\left(\mathrm{H}_{2} \mathrm{O}\right)_{6}, \quad \mathrm{YbBr}_{3} \cdot\left(\mathrm{H}_{2} \mathrm{O}\right)_{6}, \quad \mathrm{YbI}_{2} \cdot\left(\mathrm{H}_{2} \mathrm{O}\right)_{\mathrm{x}}$, and $\mathrm{TmCl}_{3} \cdot\left(\mathrm{H}_{2} \mathrm{O}\right)_{6}$ were purchased from Sigma-Aldrich and used without further purification. For ESI/MS experiments, $100-350 \mu \mathrm{M}$ solutions of the halide salts in isopropanol were prepared; no effort was made to maintain anhydrous isopropanol. The $\mathrm{YbI}_{2}$ solutions were prepared using degassed isopropanol to prevent premature oxidation. Before injection into the electrospray capillary, the $\mathrm{YbI}_{2}$ solutions were oxidized to form $\mathrm{Yb}$ (III) by a $50 \%$ dilution with non-degassed isopropanol/water (50/50). Partially deuterated isopropanol, $\mathrm{CH}_{3} \mathrm{CHODCH}_{3}$, and $\mathrm{D}_{2} \mathrm{O}$ were used to elucidate the origins of hydroxides.

\subsection{ESI/MS}

All experiments were performed using an Agilent 6340 QIT-MS with $\mathrm{MS}^{n}$ collision-induced dissociation (CID) capabilities. The instrument has a detection range of $50-2,200 \mathrm{~m} / \mathrm{z}$, with a resolution of $\sim 0.25 \mathrm{~m} / \mathrm{z}$. Mass spectra were recorded using the positive ion mode. Solutions were injected into an electrospray needle via a syringe pump and were nebulized using nitrogen gas upon exiting the needle, resulting in the creation of small droplets and 
eventually gaseous ions. The gas-phase cations entered a negatively charged capillary where they were further desolvated by dry-heated nitrogen from a liquid nitrogen dewar, which also supplied the nebulizing gas. Bare and hydrated cations passed through an ion-focusing skimmer and into two focusing octopoles for transfer into the ion trap. In the trap, specific ions were isolated by ejection of all other ions, enabling time-dependent hydration reaction studies. The temperature of the reactions in the ion trap is estimated to be $\sim 298 \mathrm{~K}$ based on the work of Gronert [25]. The detailed instrumental parameters used for the ESI/QITMS experiments are in the Supporting Information. Pseudofirst-order rate coefficients could not be determined in these experiments due to an unknown water pressure in the ion trap: only absolute reaction rates at constant water pressure are reported. It is estimated, from similar experimental setups, that the water pressure in the ion trap was $\sim 10^{-6}$ Torr [26]. Helium, present at $\sim 10^{-4}$ Torr as the buffer gas in the trap, also served to collisionally cool the reactant ions prior to the start of kinetic measurements. Rates were determined by monitoring the decay of the reactant ion and ingrowth of the product ion(s) as a function of reaction time; linear logarithmic decays of the reactant ions provided relative reaction rates. The helium provides third-body collisions that remove energy and stabilize hot product ions, which is crucial for adducts, such as hydrates. As discussed later, changes in the helium pressure substantially alter hydration rates, demonstrating that association product ions are cooled by third-body collisions. Using the variational transition-state/classical trajectory theory of $\mathrm{Su}$ and Chesnavich, the collisional rate constants for all studied ions were found to be very similar (2.1-2.2 $\times 10^{-9} \mathrm{~cm}^{3}$ molecule $\left.\mathrm{s}^{-1} \mathrm{~s}^{-1}\right)$ [27]. This similarity enables effective evaluations of relative hydration efficiencies by direct comparisons of reaction rates at a constant (albeit unknown) water pressure; for these comparisons, relative reaction rates were normalized to the fastest reaction. The constancy of the water pressure in the trap was established by periodically confirming the invariance of the hydration rate for $\mathrm{UO}_{2} \mathrm{OH}^{+}$. Most of the relative rates for comparative purposes are considered uncertain by $\pm 20 \%$; a few values have larger uncertainties, as specified in the tabulated results.

\section{Computational details}

Two different approaches of DFT were used in these studies. The PBE functionals (exchange and correlation) [28, 29] were used together with all-electron triple zeta basis sets (TZ2P) as implemented in the ADF2007.01 software package [30-32]. Scalar relativistic corrections were included via the zero-order regular approximation (ZORA) in all ADF calculations (PBE-ZORA/TZ2P, hereafter). The numerical integration parameter in $\mathrm{ADF}$ was set to 6.0 for the optimizations and 8.0 for the frequencies. The increase in the numerical integration parameter with respect to the default values (4.0 for optimization and 6.0 for frequencies) did not significantly change the energies nor the geometries of the cations but helped to eliminate spurious imaginary frequencies lower than or close to $100 \mathrm{~cm}^{-1}$ present in systems containing water molecules in the second coordination shell.

Further calculations were done using the hybrid B3LYP $[33,34]$ formulation together with the Stuttgart relativistic small-core ANO/ECP basis set for the ytterbium atom $(14 \mathrm{~s}$ 13p 10d 8f 6g)/[6s 6p 5d 4f 3g] [35-37]. This effective core potential replaces the 28 inner-shell electrons with a relativistically corrected pseudopotential. The $6-311++\mathrm{G}(\mathrm{d}$, p) basis sets of Pople and co-workers [38-40] were employed for the rest of the atoms (B3LYP/SDD-ANO, hereafter). These calculations were carried out using the GAUSSIAN 2003 package [41]. "Ultra-fine" grids were adopted with the Gaussian program.

The levels of theory were chosen based on the performance observed in our previous studies of reactions containing heavy atoms [42] and on recent theoretical studies of the hydration of $\mathrm{Ln}^{3+}$ cations [16, 18]. At both levels of theory, the use of larger basis sets was also based on some preliminary calculations performed on the bare cations, which showed an important dependence of the optimized geometries on the basis set sizes. In particular, the optimized structures of the bare cations performed using the double-zeta Stuttgart relativistic small core (12s 10p 8d 8f)/ [5s $5 \mathrm{p} 4 \mathrm{~d} 3 \mathrm{f}]$ ) for the ytterbium atom together with the B3LYP functional differ substantially from the B3LYP/ SDD-ANO results reported here, i.e., up to 35 degrees for the $\mathrm{X}-\mathrm{Yb}-\mathrm{X} / \mathrm{X}-\mathrm{Yb}-\mathrm{OH}$ angles and $0.3 \AA$ for the $\mathrm{X}-\mathrm{Yb} / \mathrm{X}-$ $\mathrm{OH}$ bond distances.

The sequential hydration reactions have been analyzed for five cations, namely, $\mathrm{Yb}(\mathrm{OH})_{2}^{+}, \mathrm{YbF}_{2}{ }^{+}, \mathrm{YbF}(\mathrm{OH})^{+}$, $\mathrm{YbCl}_{2}{ }^{+}$, and $\mathrm{YbCl}(\mathrm{OH})^{+}$. The geometry of the bare and hydrated cations (one to six water molecules) was optimized without any symmetry restrictions at both PBEZORA/TZ2P and B3LYP/SDD-ANO levels, trying several initial geometries for each species. The lowest energy structures are reported for each cation along with some relevant high-energy structures. In the case of the B3LYP/ SDD-ANO calculations, the study was limited to the addition of up to three water molecules due to excessive computational demand using this approach. These computations provided enough information to perform a comparison between the results obtained at both levels of theory. Accordingly, the discussion is preferentially focused on the PBE-ZORA/TZ2P results, and each section will present a comparison with the corresponding values obtained at the B3LYP/SDD-ANO level. 
For each optimized stationary point, analytical frequencies were calculated in order to confirm that the optimized structures were local minima on the potential energy surface of the molecules and to evaluate the zeropoint vibrational energy (ZPVE) corrections to the electronic energies. All of the reported hydration energies include the $\mathrm{ZPVE}$ correction at $0 \mathrm{~K}\left(\Delta \mathrm{E}^{0}\right)$. In addition to the $\Delta \mathrm{E}^{0}$ values, the enthalpy $\left(\Delta \mathrm{H}^{298}\right)$, entropy $\left(\Delta \mathrm{S}^{298}\right)$, and Gibbs free energy $\left(\Delta \mathrm{G}^{298}\right)$ changes (at $298 \mathrm{~K}$ ) are reported for each of the studied reactions. The accuracy of the $\Delta \mathrm{H}^{298}$ and $\Delta \mathrm{S}^{298}$ (and $\Delta \mathrm{G}^{298}$ ) values is necessarily somewhat limited by the use of the harmonic oscillator approximation to treat nuclear motion.

All of the studied cations have doublet spin states. Calculations were performed using spin-unrestricted methods, and no spin contamination problems were found.

The charge distribution was analyzed using natural population analysis (NPA) [43] and atoms in molecules (AIM) [44]. NPA was performed on the wavefunctions obtained at the B3LYP/SDD-ANO level of theory using Gaussian 2003, whereas AIM analysis was performed using ADF2009.01 on the ground-state structures obtained at the PBE-ZORA/TZ2P level of theory. Molecular images were produced using Molekel4.3 [45].

\section{Experimental results}

\subsection{ESI/MS speciation}

ESI mass spectra indicated the formation of gas-phase $\mathrm{Yb}$ (II) and $\mathrm{Yb}$ (III) cations with the chemical formulas: $\mathrm{YbX}^{+}, \mathrm{YbX}_{2}{ }^{+}$, and $\mathrm{YbX}(\mathrm{OH})^{+}(\mathrm{X}=\mathrm{OH}, \mathrm{Cl}, \mathrm{Br}, \mathrm{I})$. Additionally, hydrates of some of these species were also observed. Figures 1, 2, and 3 show typical ESI mass spectra for solutions of $\mathrm{YbCl}_{3}, \mathrm{YbBr}_{3}$, and $\mathrm{YbI}_{2}$ in isopropanol; the isopropanol, exposed to atmosphere, had absorbed an indeterminate amount of water molecules. The top spectrum in each figure shows the cationic species formed by ESI, after transfer into the trap. Transfer and trapping of ions produced by ESI can result in extensive fragmentation, desolvation and/or reactions, such that these spectra are not representative of intrinsic ESI speciation. Additionally, an inherent delay occurs between when ions are accumulated in the trap to when they are ejected to the detector, during which ions may undergo hydration and/or hydrolysis by background water in the trap. To determine whether $\mathrm{YbCl}(\mathrm{OH})^{+}$and $\mathrm{Yb}(\mathrm{OH})_{2}^{+}$ were produced during ESI or subsequently in the gas phase, a deuterated solvent experiment was performed. ESI of a $350 \mu \mathrm{M}$ solution of $\mathrm{YbCl}_{3}$ in a $80 / 20$ $\mathrm{CH}_{3} \mathrm{CHODCH}_{3} / \mathrm{D}_{2} \mathrm{O}$ mixture produced $\mathrm{YbCl}(\mathrm{OH})^{+}$and $\mathrm{Yb}(\mathrm{OH})_{2}^{+}$, but negligible $\mathrm{YbCl}(\mathrm{OD})^{+}, \mathrm{Yb}(\mathrm{OH})(\mathrm{OD})^{+}$, or
$\mathrm{Yb}(\mathrm{OD})_{2}^{+}$. These results indicate that most hydrolysis does not occur during ESI but rather that $\mathrm{YbCl}_{2}{ }^{+}$produced by ESI is hydrolyzed in the gas phase. As the hydrolysis rate of $\mathrm{YbCl}_{2}{ }^{+}$in the ion trap is too slow to account for the observed amounts of $\mathrm{YbCl}(\mathrm{OH})^{+}$and $\mathrm{Yb}(\mathrm{OH})_{2}^{+}$, hydroxide formation presumably occurs during ion transfer from the spray to the trap, where the background water pressure is much higher than in the trap.

The $\mathrm{YbX}_{2}{ }^{+}$and $\mathrm{YbX}(\mathrm{OH})^{+}$ions, and all four hydrates of each, were observed in the ESI mass spectra, except for the $\mathrm{YbBr}_{2}^{+}, \mathrm{YbI}_{2}^{+}$, and $\mathrm{YbI}_{2}^{+} \cdot\left(\mathrm{H}_{2} \mathrm{O}\right)$ ions. These latter three ion complexes could have been absent because $\mathrm{YbBr}_{2}^{+} \cdot\left(\mathrm{H}_{2} \mathrm{O}\right)$ and $\mathrm{YbI}_{2}{ }^{+} \cdot\left(\mathrm{H}_{2} \mathrm{O}\right)_{2}$ remain intact throughout the ESI and ion transport processes, which is consistent with the rationale below regarding stabilization of halide hydrates with low vibrational frequencies. The bottom spectra in Figs. 1, 2, and 3 show the ionic species generated after a one-second reaction time in the trap. Although bare $\mathrm{YbCl}_{2}{ }^{+}$and its first three hydrates were not definitively observed in any mass spectra due to isotopic interferences (Fig. 1, top), $\mathrm{YbCl}_{2}{ }^{+} \cdot\left(\mathrm{H}_{2} \mathrm{O}\right)_{4}$ was identified after hydration (Fig. 1, bottom), indicating the presence of bare and/or partially hydrated $\mathrm{YbCl}_{2}{ }^{+}$in the parent mass spectrum.

\subsection{Gas-phase hydration}

The biligated $\mathrm{Yb}$ species and/or their hydrates, $\mathrm{YbX}_{2}{ }^{+} \cdot\left(\mathrm{H}_{2} \mathrm{O}\right)_{n}$ and $\mathrm{YbX}(\mathrm{OH})^{+} \cdot\left(\mathrm{H}_{2} \mathrm{O}\right)_{n}(\mathrm{X}=\mathrm{OH}, \mathrm{Cl}, \mathrm{Br}$, $\mathrm{I} ; n=0-3)$, hydrated in the gas phase. The gas-phase $\mathrm{YbX}_{2}{ }^{+}$and $\mathrm{YbX}(\mathrm{OH})^{+}$species were hydrated by up to four water molecules, as demonstrated by allowing the ions to react with background water in the ion trap. A key observation was that hydration for all $\mathrm{YbX}_{2}{ }^{+}$and $\mathrm{YbX}(\mathrm{OH})^{+}$species terminated at four coordinated water molecules under our experimental conditions; no pentahydrates were observed even with the maximum accessible reaction time of $10 \mathrm{~s}$, as illustrated for $\mathrm{Yb}(\mathrm{OH})_{2}^{+}$in Fig. 4. However, a very weak $\mathrm{Yb}(\mathrm{OH})_{2}^{+} \cdot\left(\mathrm{H}_{2} \mathrm{O}\right)_{5}$ peak was observed with a relatively short reaction time of $200 \mathrm{~ms}$ and an order of magnitude increase in water pressure in the ion trap by adding water to the trap through the helium gas inlet.

The monoligated $\mathrm{Yb}$ species produced by ESI, $\mathrm{YbX}^{+}$ ( $\mathrm{X}=\mathrm{OH}, \mathrm{Cl}, \mathrm{Br}, \mathrm{I}$ ), did not hydrate in the gas phase even using long reaction times. However, hydrates of $\mathrm{YbI}^{+}$were produced directly by ESI (Fig. 3, top). Changes in the relative intensities of the $\mathrm{YbI}^{+} \cdot\left(\mathrm{H}_{2} \mathrm{O}\right)_{\mathrm{x}}$ peaks upon application of hydration delays indicated hydration of the hydrates. For example, the intensities of the $\mathrm{YbI}^{+} \cdot\left(\mathrm{H}_{2} \mathrm{O}\right)_{3}$ and $\mathrm{YbI}^{+} \cdot\left(\mathrm{H}_{2} \mathrm{O}\right)_{4}$ peaks relative to $\mathrm{YbI}^{+}$, which did not hydrate, were respectively 4 and $0.3 \%$ in the ESI mass spectrum and 17 and $15 \%$ after a one-second hydration time. 
Fig. 1 ESI/MS of $\mathrm{YbCl}_{3}$ in isopropanol. The top spectrum is from ESI/MS. The bottom spectrum shows the gas-phase speciation after a one-second reaction period in the trap. The bare $\mathrm{YbCl}_{2}{ }^{+}$species was not definitively identified

Fig. 2 ESI/MS of $\mathrm{YbBr}_{3}$ in isopropanol. The top spectrum is from ESI/MS. The bottom spectrum shows the gas-phase speciation after a one-second reaction period in the trap
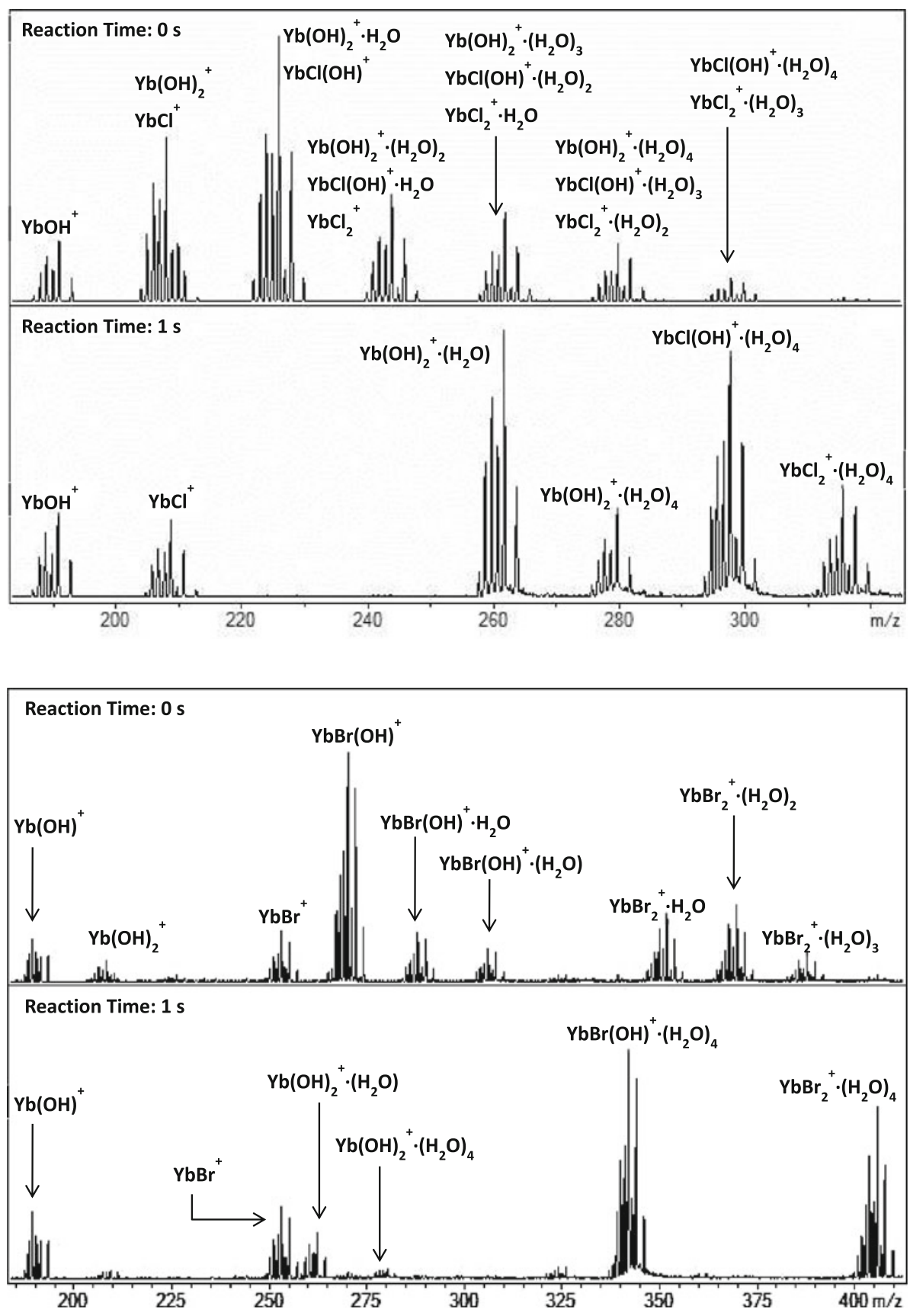

\subsection{Gas-phase hydration kinetics}

Pseudo-first-order hydration kinetics were determined from logarithmic decay plots, such as in Figs. 5 and 6. Fewer than half of the isolated ions hydrolyzed in the gas phase, as discussed later. For the halide and hydroxide halide ions, gas-phase hydrolysis rates-i.e., replacement of a halide by a hydroxide upon reaction with water-were obtained from decay plots, such as in Fig. 6; the hydrolysis contribution was then subtracted from the total reaction rate to determine the hydration rates. In most cases, no hydrolysis was observed and the hydration rate was the total reaction rate.
In cases where hydrolysis and hydration of the isolated ion were the only reaction pathways, the total reaction rate was the sum of the two rates, e.g., the total reaction rate for $\mathrm{YbBr}_{2}^{+} \cdot\left(\mathrm{H}_{2} \mathrm{O}\right)_{2}$ was the sum of the hydration rate, Eq. 1, and the hydrolysis rate, Eq. 2.

$\mathrm{YbBr}_{2}^{+} \cdot\left(\mathrm{H}_{2} \mathrm{O}\right)_{2}+\mathrm{H}_{2} \mathrm{O} \rightarrow \mathrm{YbBr}_{2}^{+} \cdot\left(\mathrm{H}_{2} \mathrm{O}\right)_{3}$

$\mathrm{YbBr}_{2}^{+} \cdot\left(\mathrm{H}_{2} \mathrm{O}\right)_{2}+\mathrm{H}_{2} \mathrm{O} \rightarrow \mathrm{YbBr}(\mathrm{OH})^{+} \cdot\left(\mathrm{H}_{2} \mathrm{O}\right)_{2}+\mathrm{HBr}$

However, in a few instances, a produced hydrate of the isolated ion also hydrolyzed and contributed to the total reaction rate. Using $\mathrm{YbBr}_{2}^{+} \cdot\left(\mathrm{H}_{2} \mathrm{O}\right)$ as an example, the total 
Fig. 3 ESI/MS of $\mathrm{YbI}_{2}$ in isopropanol. The top spectrum is from ESI/MS. The bottom spectrum shows the gas-phase speciation after a one-second reaction period in the trap

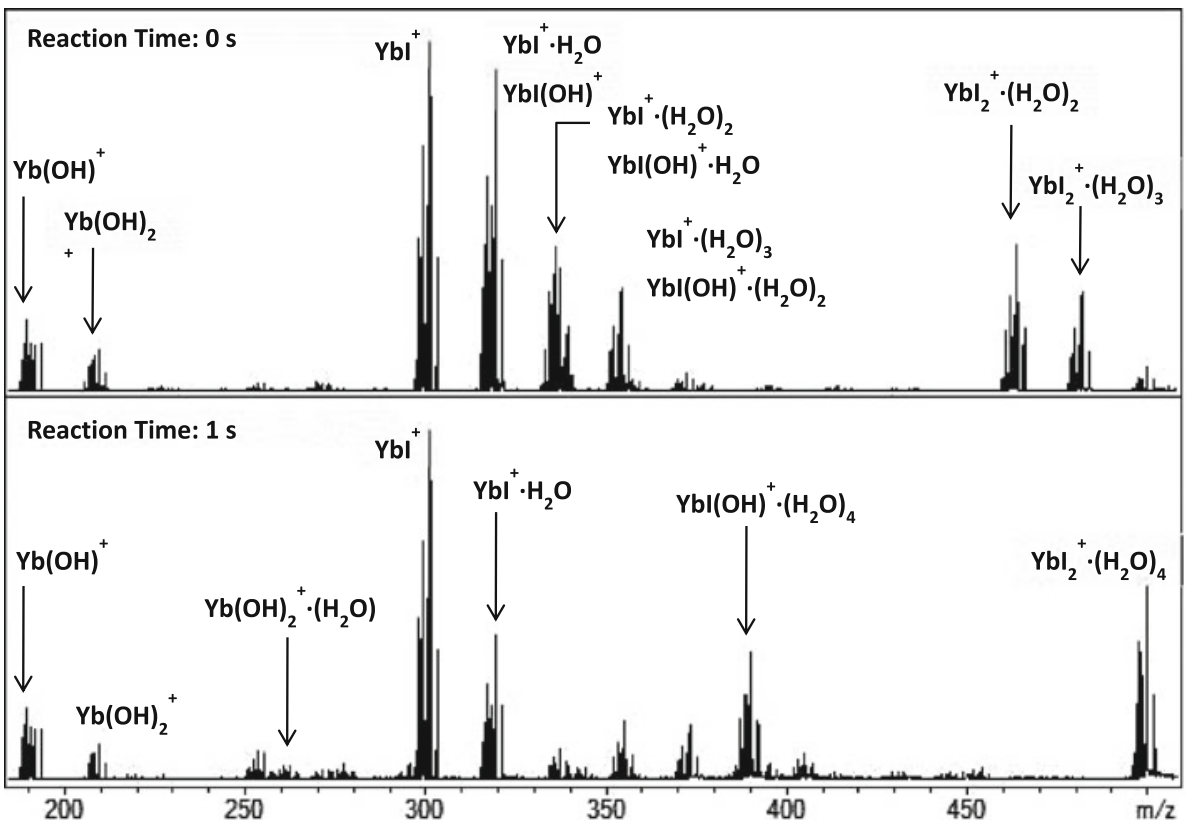

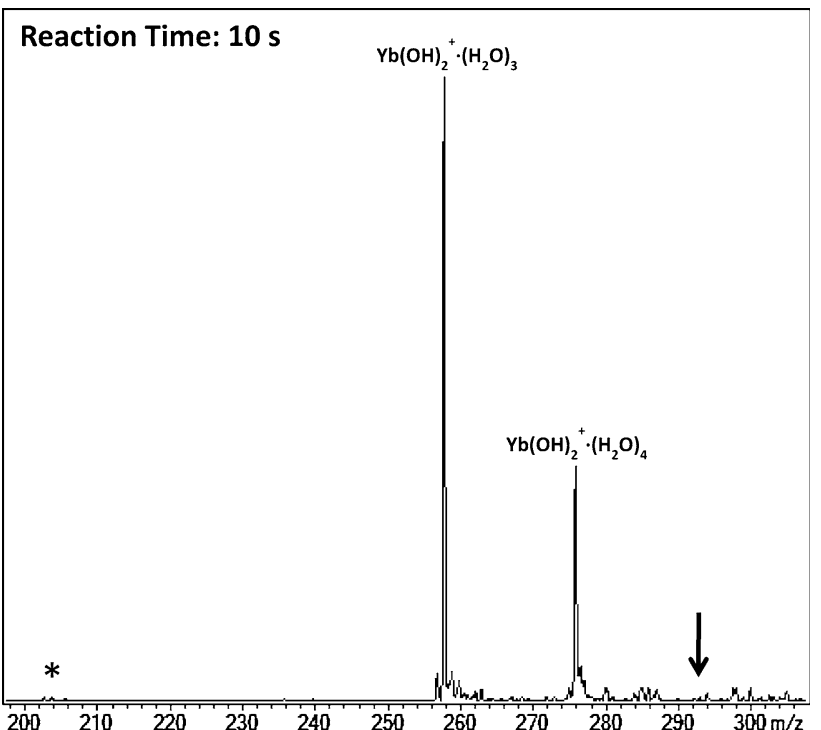

Fig. 4 Isolated $\mathrm{Yb}(\mathrm{OH})_{2}^{+}$with a 10 -s reaction time. The asterisk represents the location of the isolated ion. The arrow indicates where the pentahydrate would appear

reaction rate was the sum of the hydration rate, Eq. 3, hydrolysis rate, Eq. 4, and the hydrolysis rate of the produced hydrate, Eq. 2.

$\mathrm{YbBr}_{2}^{+} \cdot\left(\mathrm{H}_{2} \mathrm{O}\right)+\mathrm{H}_{2} \mathrm{O} \rightarrow \mathrm{YbBr}_{2}^{+} \cdot\left(\mathrm{H}_{2} \mathrm{O}\right)_{2}$

$\mathrm{YbBr}_{2}^{+} \cdot\left(\mathrm{H}_{2} \mathrm{O}\right)+\mathrm{H}_{2} \mathrm{O} \rightarrow \mathrm{YbBr}(\mathrm{OH})^{+} \cdot\left(\mathrm{H}_{2} \mathrm{O}\right)+\mathrm{HBr}$

In these instances, the reported hydration rates include the hydrolysis rate of the produced hydrate, i.e., the sum of the rates for Eq. 3 and Eq. 2, because the hydrolyzed hydrate is still a product of the hydration pathway. Because the water pressure in the trap was only estimated as $\sim 10^{-6}$ Torr,

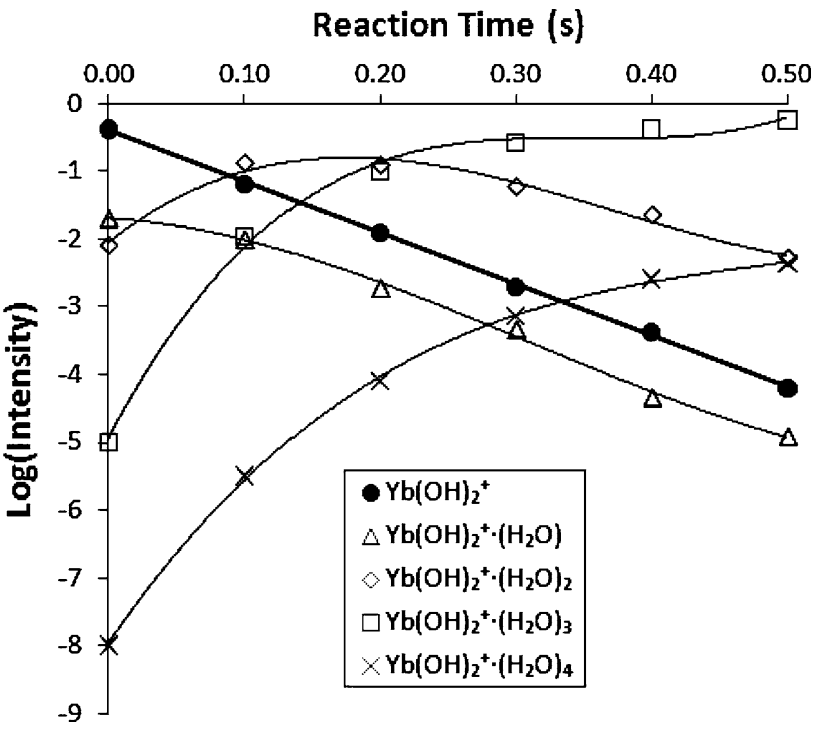

Fig. 5 Time profile of $\mathrm{Yb}(\mathrm{OH})_{2}^{+}$hydration. $\mathrm{Yb}(\mathrm{OH})_{2}^{+}$ions produced from ESI of solutions of $\mathrm{YbCl}_{3}$ in isopropanol were isolated and hydrated by water in the ion trap. The linear decay provides the hydration rate for $\mathrm{Yb}(\mathrm{OH})_{2}^{+}$

kinetics are reported as absolute rates (i.e., $\mathrm{s}^{-1}$ ), not as rate coefficients. Using the $\mathrm{UO}_{2}(\mathrm{OH})^{+}$hydration reaction for calibration and maintaining a constant helium pressure, it was confirmed that the water pressure was invariant to within $<10 \%$ such that the measured hydration rates can be directly compared with one another. The intent here was not to measure rate coefficients, which depend on the cooling gas pressure, but rather to compare the relative rates of hydration.

Due to experimental limitations-isotopic interferences and/or low ion intensities-hydration rates could not be 
Fig. 6 Time profile of $\mathrm{YbCl}(\mathrm{OH})^{+}$hydration (left) and hydrolysis (right). $\mathrm{YbCl}(\mathrm{OH})^{+}$ ions were isolated and hydrated or hydrolyzed by water in the ion trap. Hydration and hydrolysis kinetics were determined by altering the reaction time in the ion trap
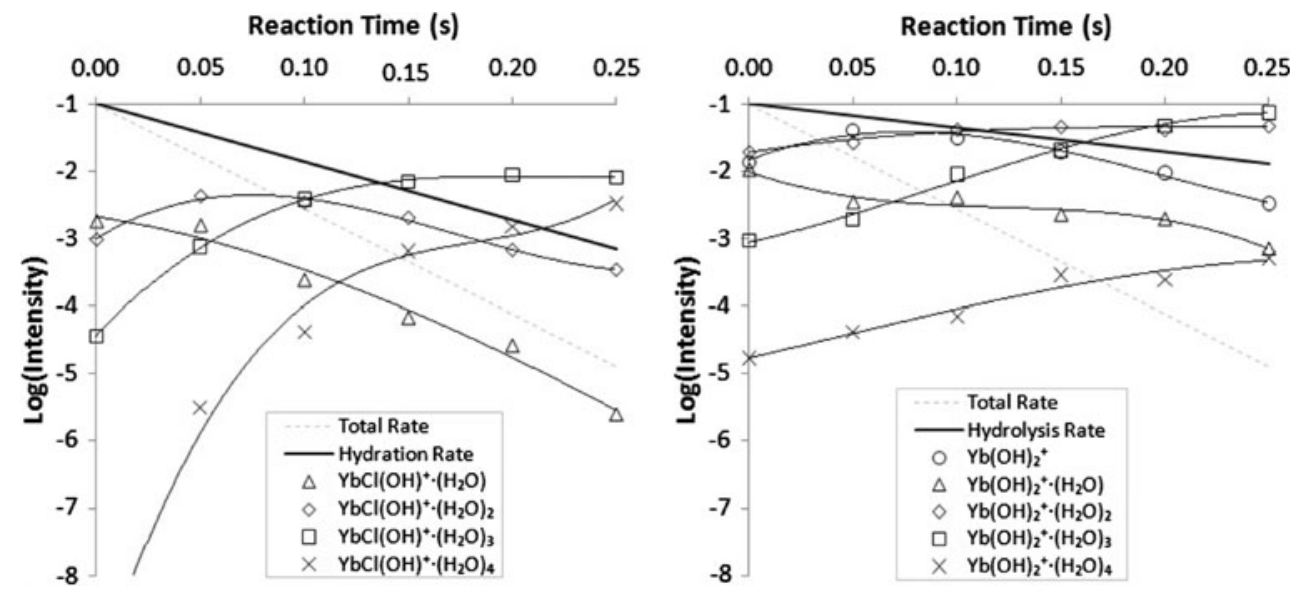

effectively measured for several of the biligated ytterbium ions. In Table 1 , the measured relative hydration rates are given. The hydration rates were normalized to the fastest measured hydration rate, which is the essentially identical second hydration rates of $\mathrm{Yb}(\mathrm{OH})_{2}^{+}$and $\mathrm{Tm}(\mathrm{OH})_{2}^{+}$as seen in Table 2; these normalized rates are shown in parentheses. A graphical representation of the measured rates as a function of hydration step is shown in Fig. 7 to illustrate the trends in hydration kinetics. The relatively slow hydration of $\mathrm{Yb}(\mathrm{OH})_{2}^{+}$is evident in Figs. 1, 2, and 3: $\mathrm{YbX}_{2}{ }^{+}$and $\mathrm{YbX}(\mathrm{OH})^{+}$are fully hydrated to the tetrahydrate after $1 \mathrm{~s}$ but $\mathrm{Yb}(\mathrm{OH})_{2}^{+}$is not; the comparative kinetics are discussed later.

To supplement the ytterbium results, thulium chloride was studied. Thulium, which is monoisotopic ${ }^{169} \mathrm{Tm}$, is the lighter neighboring lanthanide to $\mathrm{Yb}$ such that the hydration rates of the corresponding ligated $\mathrm{Tm}(\mathrm{III})$ and $\mathrm{Yb}(\mathrm{III})$ ions should be very similar. The mass spectra for the $\mathrm{TmCl}_{3}$ solutions were similar to those for the $\mathrm{YbCl}_{3}$ solutions, and similar hydrolysis was observed, as shown in Fig. 8. The intensities of the peaks for $\mathrm{TmCl}_{2}{ }^{+}$and its hydrates were very weak such that hydration rates could

Table $1 \mathrm{YbX}_{2}{ }^{+}$and $\mathrm{YbX}(\mathrm{OH})^{+}$hydration kinetics determined from isolated species created by ESI-MS

\begin{tabular}{lccccc}
\hline Hydration step & $\mathrm{Yb}(\mathrm{OH})_{2}^{+}$ & $\mathrm{YbCl}(\mathrm{OH})^{+}$ & $\mathrm{YbBr}_{2}^{+}$ & $\mathrm{YbBr}(\mathrm{OH})^{+}$ & $\mathrm{YbI}_{2}^{+}$ \\
\hline $\mathrm{Z}^{+}+\mathrm{H}_{2} \mathrm{O} \rightarrow \mathrm{Z}^{+} \cdot\left(\mathrm{H}_{2} \mathrm{O}\right)$ & $7.2(28)$ & $10.8(42)$ & & $2.7(10)$ & $11(42)$ \\
$\mathrm{Z}^{+} \cdot\left(\mathrm{H}_{2} \mathrm{O}\right)+\mathrm{H}_{2} \mathrm{O} \rightarrow \mathrm{Z}^{+} \cdot\left(\mathrm{H}_{2} \mathrm{O}\right)_{2}$ & $26(100)$ & $20(77)^{\mathrm{a}}$ & $16(62)$ & $20(77)$ & $17(65)$ \\
$\mathrm{Z}^{+} \cdot\left(\mathrm{H}_{2} \mathrm{O}\right)_{2}+\mathrm{H}_{2} \mathrm{O} \rightarrow \mathrm{Z}^{+} \cdot\left(\mathrm{H}_{2} \mathrm{O}\right)_{3}$ & $7.0(27)$ & & $14(54)$ & $10(38)$ & $11(42)$ \\
$\mathrm{Z}^{+} \cdot\left(\mathrm{H}_{2} \mathrm{O}\right)_{3}+\mathrm{H}_{2} \mathrm{O} \rightarrow \mathrm{Z}^{+} \cdot\left(\mathrm{H}_{2} \mathrm{O}\right)_{4}$ & & & $12(46)$ & $4.2(16)$ & $9.3(36)$ \\
\hline
\end{tabular}

Values are reported in $\mathrm{s}^{-1}$ at constant water pressure. Values in parentheses are percentages of the reaction rates normalized to the fastest hydration, the second hydration of $\mathrm{Yb}(\mathrm{OH})_{2}^{+}$and $\mathrm{Tm}(\mathrm{OH})_{2}^{+}$. As discussed in the Sect. 2, all studied ions were thermalized

${ }^{a}$ This relative rate has an inordinately large uncertainty, approximately a factor of two, primarily due to a very low signal intensity

Table $2 \mathrm{Tm}$ and $\mathrm{Yb}$ hydration kinetics determined from isolated species created by ESI-MS

\begin{tabular}{|c|c|c|c|c|}
\hline Hydration step & $\operatorname{Tm}(\mathrm{OH})_{2}^{+}$ & $\mathrm{Yb}(\mathrm{OH})_{2}^{+}$ & $\operatorname{TmCl}(\mathrm{OH})^{+}$ & $\mathrm{YbCl}(\mathrm{OH})^{+}$ \\
\hline $\mathrm{Z}^{+}+\mathrm{H}_{2} \mathrm{O} \rightarrow \mathrm{Z}^{+} \cdot\left(\mathrm{H}_{2} \mathrm{O}\right)$ & $7.9(31)$ & $7.2(28)$ & $9.9(38)$ & 10.8 \\
\hline $\mathrm{Z}^{+} \cdot\left(\mathrm{H}_{2} \mathrm{O}\right)+\mathrm{H}_{2} \mathrm{O} \rightarrow \mathrm{Z}^{+} \cdot\left(\mathrm{H}_{2} \mathrm{O}\right)_{2}$ & $26(100)$ & $26(100)$ & $21(81)^{\mathrm{a}}$ & $20(77)^{\mathrm{b}}$ \\
\hline $\mathrm{Z}^{+} \cdot\left(\mathrm{H}_{2} \mathrm{O}\right)_{2}+\mathrm{H}_{2} \mathrm{O} \rightarrow \mathrm{Z}^{+} \cdot\left(\mathrm{H}_{2} \mathrm{O}\right)_{3}$ & $6.4(25)$ & $7.0(27)$ & $13(50)$ & \\
\hline $\mathrm{Z}^{+} \cdot\left(\mathrm{H}_{2} \mathrm{O}\right)_{3}+\mathrm{H}_{2} \mathrm{O} \rightarrow \mathrm{Z}^{+} \cdot\left(\mathrm{H}_{2} \mathrm{O}\right)_{4}$ & $0.062(0.24)$ & & & \\
\hline
\end{tabular}

Values are reported in $\mathrm{s}^{-1}$ at constant water pressure. Values in parentheses are percentages of the reaction rates normalized to the fastest hydration, the second hydration of $\mathrm{Yb}(\mathrm{OH})_{2}^{+}$and $\mathrm{Tm}(\mathrm{OH})_{2}^{+}$. As discussed in the Sect. 2, all studied ions were thermalized

${ }^{\text {a }}$ This relative rate has a large uncertainty, approximately $\pm 50 \%$, due to experimental limitations

b This relative rate has an inordinately large uncertainty, approximately a factor of two, primarily due to a very low signal intensity 


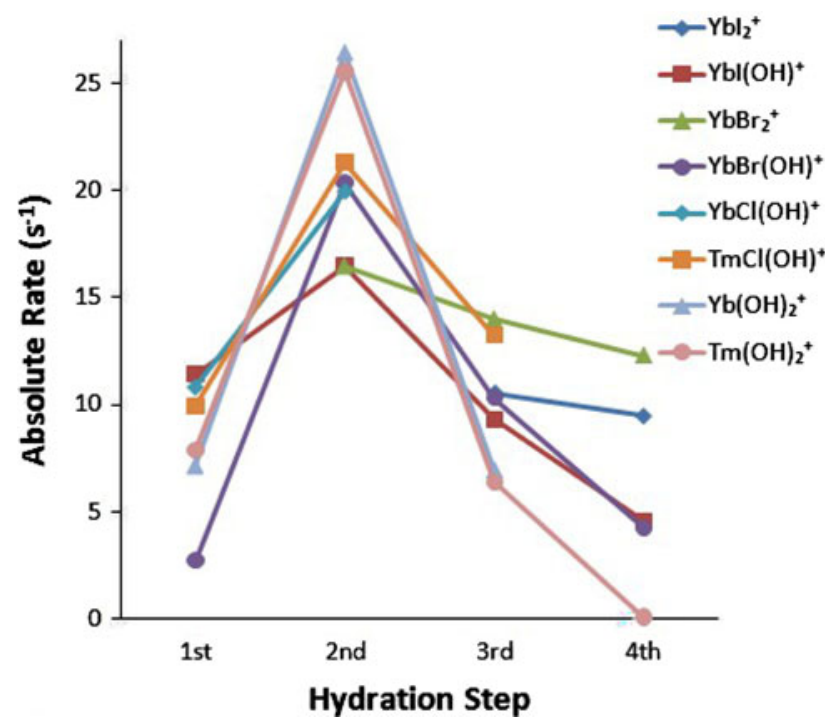

Fig. 7 Absolute hydration rates at constant water pressure, plotted as a function of hydration step. The second hydration for all studied ion complexes was the fastest; the fourth hydration was the slowest

not be determined. The hydration rates for $\operatorname{Tm}(\mathrm{OH})_{2}^{+}$, $\mathrm{TmCl}(\mathrm{OH})^{+}$, and their hydrates were measured and were found to be similar to the $\mathrm{Yb}$ analogues-see Table 2 . Given the close similarity between the rates for the first three hydrations of $\mathrm{Yb}(\mathrm{OH})_{2}^{+}$and $\mathrm{Tm}(\mathrm{OH})_{2}^{+}$, the missing rate for the fourth hydration of $\mathrm{Yb}(\mathrm{OH})_{2}^{+}$is expected to be substantially slower than the other hydrations of $\mathrm{Yb}(\mathrm{OH})_{2}^{+}$, perhaps roughly two orders of magnitude slower, as for $\operatorname{Tm}(\mathrm{OH})_{2}^{+} \cdot\left(\mathrm{H}_{2} \mathrm{O}\right)_{3}$. Likewise, the undetermined rate for the third hydration of $\mathrm{YbCl}(\mathrm{OH})^{+}$is expected to be slower than the second, as for $\mathrm{TmCl}(\mathrm{OH})^{+}$.
The first and third hydration steps for biligated complexes generally exhibited similar rates, whereas the second hydration step was relatively faster, and the fourth was relatively slower. The first hydration of $\operatorname{YbBr}(\mathrm{OH})^{+}$was aberrantly slow. Referring to Fig. 7, the following general ordering of hydration rates results from the measured kinetics: 1 st $<2$ nd $>3$ rd $>4$ th.

In the $\mathrm{TmCl}_{3}$ experiments, $\mathrm{TmO}^{+}$was observed (Fig. 8), whereas from $\mathrm{YbCl}_{3}$, no $\mathrm{YbO}^{+}$was observed (Fig. 1). This difference is attributed to the propensity for $\mathrm{Yb}$ to exist in the divalent oxidation state, as in $\mathrm{YbOH}^{+}$. Given this disparity between $\mathrm{Yb}$ and $\mathrm{Tm}$, it should be emphasized that the experimental results reveal that hydration of the biligated trivalent $\mathrm{Yb}$ and $\mathrm{Tm}$ ions is similar: hydration is primarily an electrostatic interaction that does not involve a change in oxidation state.

\subsection{Gas-phase hydrolysis}

Hydrolysis was observed in the ESI experiments performed on ytterbium halide solutions. The $\mathrm{YbX}(\mathrm{OH})^{+}$and $\mathrm{Yb}(\mathrm{OH})_{2}^{+}$species were abundant in the parent ESI spectra from the halide solutions. As discussed earlier, the deuterium substitution experiments revealed that hydroxide formation occurs after ESI and before trapping, during ion desolvation and transport in the high-pressure regime of the instrument. In the $\mathrm{X}$-ray diffraction studies previously mentioned, it has been demonstrated that hydrated $\mathrm{Ln}^{3+}$ ions, $\operatorname{Ln}\left(\mathrm{H}_{2} \mathrm{O}\right)_{8,9}^{3+}$, not hydrolyzed lanthanides, $\mathrm{Ln}(\mathrm{OH})_{2}^{+}$, are the abundant species in aqueous solutions under conditions such as those employed in this work $[8,9]$. The absence of $\mathrm{YbCl}(\mathrm{OD})^{+} \mathrm{Yb}(\mathrm{OD})_{2}^{+}$in the deuterium
Fig. $8 \mathrm{ESI} / \mathrm{MS}$ of $\mathrm{TmCl}_{3}$ in isopropanol. The top spectrum is the ESI/MS. The bottom spectrum shows the gas-phase speciation after a one-second reaction period in the trap. The $\mathrm{TmCl}_{2}{ }^{+}$species was not definitively identified

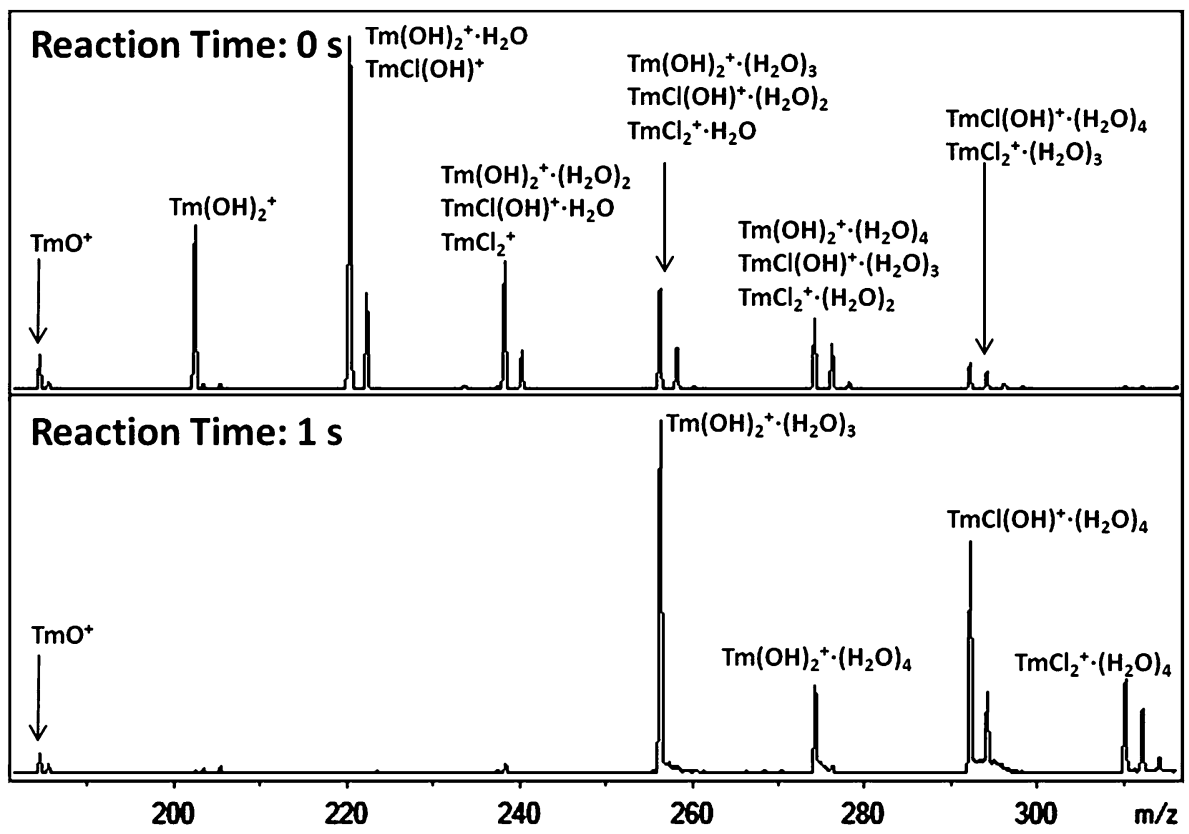


substitution experiments confirms that these hydroxides do not originate from solution, but rather form in the gas phase. Hydrolysis may occur in the ion trap when a reaction time is applied - this was confirmed by results such as those shown in Fig. 6. All halide-containing ions hydrolyzed in the trap, with rates slower than for hydration: the hydrolysis reactions and rates are in Table 3 . As discussed in the previous section, the total decay rate of the isolated ion is composed of the hydration rate, the hydrolysis rate, and, when applicable, the hydrolysis rate of produced hydrates. The percentage of hydrolyzed species in the mass spectra of the isolated reactant was used to determine the hydrolysis rate as a fraction of the total reaction rate. The large difference between the hydrolysis rates for $\mathrm{TmCl}(\mathrm{OH})^{+}(k=1.0)$ and $\mathrm{YbCl}(\mathrm{OH})^{+}(k=3.2)$ is notable. The hydration rates for these two ions are very similar, as expected, because the ion-water association interaction is essentially electrostatic. In contrast, the disparate hydrolysis rates evidently reflect different chemistries of the two ions. Another example of the differing chemistries of $\mathrm{Yb}$ and $\mathrm{Tm}$ comes from a study of $\mathrm{D}_{2} \mathrm{O}$ reactions with gas-phase lanthanide cations where the primary reaction channel for $\mathrm{Tm}^{+}$was $\mathrm{D}_{2} \mathrm{O}$ addition, whereas for $\mathrm{Yb}^{+}$, OD transfer was dominant [46].

The relative intensities of the isotopically separated fully hydrated biligated species after a one-second hydration period (Figs. 1, 2, 3) provide an indication of the relative intensities of the dihalide, $\mathrm{YbX}_{2}^{+}$, the partially hydrolyzed $\mathrm{YbX}(\mathrm{OH})^{+}$, and the fully hydrolyzed $\mathrm{Yb}(\mathrm{OH})_{2}^{+}$ produced during the period between ESI and trapping. Hydrolysis was most prevalent for the chloride and least for the iodide, as evident from the comparative abundances of the $\mathrm{YbX}_{2}{ }^{+}$and $\mathrm{YbX}(\mathrm{OH})^{+}$hydrates in Figs. 1, 2, and 3. After a one-second hydration period, the relative intensities of the hydrates of $\mathrm{Yb}(\mathrm{OH})_{2}^{+} / \mathrm{YbX}(\mathrm{OH})^{+} / \mathrm{YbX}_{2}{ }^{+}$were $46 \%$ / $36 \% / 18 \%$ for $\mathrm{X}=\mathrm{Cl} ; 11 \% / 51 \% / 39 \%$ for $\mathrm{X}=\mathrm{Br}$; and $7 \% /$ $38 \% / 55 \%$ for $\mathrm{X}=\mathrm{I}$.

\section{Computational results}

\subsection{Bare cation structures}

Figures 9, 10, 11, 12, and 13 show the optimized geometries of the $\mathrm{YbX}_{2}{ }^{+}$and $\mathrm{YbX}(\mathrm{OH})^{+}(\mathrm{X}=\mathrm{OH}, \mathrm{F}$, and $\mathrm{Cl})$ bare cations as well as the lowest energy structures of the successive hydrates. High-energy structures are reported for some relevant penta- and hexahydrates. In the chemical formulas of the hydrates, water molecules in the second solvation shell are shown in italics.

The bare halide/hydroxide ions exhibit folded structures with $\mathrm{X}-\mathrm{Yb}-\mathrm{X}$ and $\mathrm{X}-\mathrm{Yb}-\mathrm{OH}$ angles that vary between 105 and 116 degrees. Bond distances range from $1.91 \AA(\mathrm{Yb}-$ $\mathrm{F})$ in $\mathrm{YbF}_{2}^{+}$to $2.40 \AA(\mathrm{Yb}-\mathrm{Cl})$ in $\mathrm{YbCl}(\mathrm{OH})^{+}$(PBEZORA/TZ2P). The B3LYP/SDD-ANO bond distances differ from the PBE-ZORA/TZ2P values by between 0.01 and $0.05 \AA$, and the largest difference found for angles is 11 degrees.

AIM analysis indicates that the atomic metal charges vary from $2.213 \mathrm{au}$ in $\mathrm{YbF}_{2}{ }^{+}$to $1.809 \mathrm{au}$ in $\mathrm{YbCl}_{2}{ }^{+}$. The corresponding values obtained using the NPA approach are similar, with values of 2.392 and 1.829 au, respectively. A comparison between the atomic charges obtained using the different methodologies shows that the largest difference is about 0.38 au. In general, greater positive metal charges are obtained using NPA on the B3LYP/SDDANO-optimized wavefunctions. A complete report of the charge distribution for all of the ground state (GS) bare and hydrated cations is included in the Supporting Information (Tables S1 to S5).

\subsection{Hydrate structures}

The addition of the first water molecule produces, in general, pyramidal structures with $\mathrm{Yb}-\mathrm{OH}_{2}$ distances that range between $2.28 \AA$ in $\mathrm{YbF}_{2}{ }^{+} \cdot\left(\mathrm{H}_{2} \mathrm{O}\right)$ and $2.33 \AA$ in
Table 3 Hydrolysis kinetics for isolated species produced by ESI

Rate values are reported in $\mathrm{s}^{-1}$ at constant water pressure ( $\sim 10^{-6}$ Torr $)$

\begin{tabular}{|c|c|c|}
\hline Isolated ion & Hydrolysis reaction & $k$ \\
\hline $\mathrm{YbCl}(\mathrm{OH})^{+}$ & $\mathrm{YbCl}(\mathrm{OH})^{+}+\mathrm{H}_{2} \mathrm{O} \rightarrow \mathrm{Yb}(\mathrm{OH})_{2}^{+}+\mathrm{HCl}$ & 3.2 \\
\hline $\mathrm{YbCl}(\mathrm{OH})^{+} \cdot\left(\mathrm{H}_{2} \mathrm{O}\right)$ & $\mathrm{YbCl}(\mathrm{OH})^{+} \cdot\left(\mathrm{H}_{2} \mathrm{O}\right)+\mathrm{H}_{2} \mathrm{O} \rightarrow \mathrm{Yb}(\mathrm{OH})_{2}^{+} \cdot\left(\mathrm{H}_{2} \mathrm{O}\right)+\mathrm{HCl}$ & 3.9 \\
\hline $\mathrm{TmCl}(\mathrm{OH})^{+}$ & $\operatorname{TmCl}(\mathrm{OH})^{+}+\mathrm{H}_{2} \mathrm{O} \rightarrow \operatorname{Tm}(\mathrm{OH})_{2}^{+}+\mathrm{HCl}$ & 1.0 \\
\hline $\operatorname{TmCl}(\mathrm{OH})^{+} \cdot\left(\mathrm{H}_{2} \mathrm{O}\right)$ & $\operatorname{TmCl}(\mathrm{OH})^{+} \cdot\left(\mathrm{H}_{2} \mathrm{O}\right)+\mathrm{H}_{2} \mathrm{O} \rightarrow \operatorname{Tm}(\mathrm{OH})_{2}^{+} \cdot\left(\mathrm{H}_{2} \mathrm{O}\right)+\mathrm{HCl}$ & 3.3 \\
\hline $\operatorname{TmCl}(\mathrm{OH})^{+} \cdot\left(\mathrm{H}_{2} \mathrm{O}\right)_{2}$ & $\operatorname{TmCl}(\mathrm{OH})^{+} \cdot\left(\mathrm{H}_{2} \mathrm{O}\right)_{2}+\mathrm{H}_{2} \mathrm{O} \rightarrow \operatorname{Tm}(\mathrm{OH})_{2}^{+} \cdot\left(\mathrm{H}_{2} \mathrm{O}\right)_{2}+\mathrm{HCl}$ & 1.1 \\
\hline $\mathrm{YbBr}_{2}^{+} \cdot\left(\mathrm{H}_{2} \mathrm{O}\right)$ & $\mathrm{YbBr}_{2}^{+} \cdot\left(\mathrm{H}_{2} \mathrm{O}\right)+\mathrm{H}_{2} \mathrm{O} \rightarrow \mathrm{YbBr}(\mathrm{OH})^{+} \cdot\left(\mathrm{H}_{2} \mathrm{O}\right)+\mathrm{HBr}$ & 1.1 \\
\hline $\mathrm{YbBr}_{2}^{+} \cdot\left(\mathrm{H}_{2} \mathrm{O}\right)_{2}$ & $\mathrm{YbBr}_{2}^{+} \cdot\left(\mathrm{H}_{2} \mathrm{O}\right)_{2}+\mathrm{H}_{2} \mathrm{O} \rightarrow \mathrm{YbBr}(\mathrm{OH})^{+} \cdot\left(\mathrm{H}_{2} \mathrm{O}\right)_{2}+\mathrm{HBr}$ & 0.054 \\
\hline $\mathrm{YbBr}(\mathrm{OH})^{+}$ & $\mathrm{YbBr}(\mathrm{OH})^{+}+\mathrm{H}_{2} \mathrm{O} \rightarrow \mathrm{Yb}(\mathrm{OH})_{2}^{+}+\mathrm{HBr}$ & 0.36 \\
\hline $\mathrm{YbI}_{2}{ }^{+} \cdot\left(\mathrm{H}_{2} \mathrm{O}\right)_{2}$ & $\mathrm{YbI}_{2}^{+} \cdot\left(\mathrm{H}_{2} \mathrm{O}\right)_{2}+\mathrm{H}_{2} \mathrm{O} \rightarrow \mathrm{YbI}(\mathrm{OH})^{+} \cdot\left(\mathrm{H}_{2} \mathrm{O}\right)_{2}+\mathrm{HI}$ & 0.87 \\
\hline $\mathrm{YbI}(\mathrm{OH})^{+}$ & $\mathrm{YbI}(\mathrm{OH})^{+}+\mathrm{H}_{2} \mathrm{O} \rightarrow \mathrm{Yb}(\mathrm{OH})_{2}^{+}+\mathrm{HI}$ & 0.44 \\
\hline $\mathrm{YbI}(\mathrm{OH})^{+} \cdot\left(\mathrm{H}_{2} \mathrm{O}\right)$ & $\mathrm{YbI}(\mathrm{OH})^{+} \cdot\left(\mathrm{H}_{2} \mathrm{O}\right)+\mathrm{H}_{2} \mathrm{O} \rightarrow \mathrm{Yb}(\mathrm{OH})_{2}^{+} \cdot\left(\mathrm{H}_{2} \mathrm{O}\right)+\mathrm{HI}$ & 0.084 \\
\hline
\end{tabular}


Fig. 9 Lowest energy equilibrium structures for $\mathrm{Yb}(\mathrm{OH})_{2}^{+} \cdot\left(\mathrm{H}_{2} \mathrm{O}\right)_{\mathrm{n}}, n=0-6$. Distances $(\AA)$ and angles (degrees) are given. B3LYP/ SDD-ANO results are in parentheses. $\mathrm{Yb}(\mathrm{OH})_{2}^{+} \cdot\left(\mathrm{H}_{2} \mathrm{O}\right)_{5}$ and $\mathrm{Yb}(\mathrm{OH})_{2}^{+} \cdot\left(\mathrm{H}_{2} \mathrm{O}\right)_{5}\left(\mathrm{H}_{2} \mathrm{O}\right)$ are high-energy species. The relative energies of these latter species with respect to the ground state structures, $\mathrm{Yb}(\mathrm{OH})_{2}^{+} \cdot\left(\mathrm{H}_{2} \mathrm{O}\right)_{4}\left(\mathrm{H}_{2} \mathrm{O}\right)$ and $\mathrm{Yb}(\mathrm{OH})_{2}^{+} \cdot\left(\mathrm{H}_{2} \mathrm{O}\right)_{4}\left(\mathrm{H}_{2} \mathrm{O}\right)_{2}$, respectively, are both $20 \mathrm{~kJ} \mathrm{~mol}^{-1}$. Italics denote water molecules in the second solvation shell

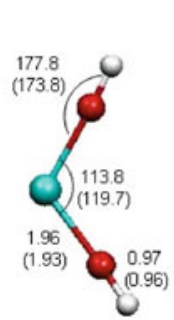

$\mathrm{Yb}(\mathrm{OH})_{2}^{+}$

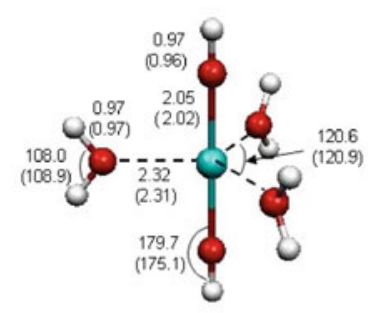

$\mathrm{Yb}(\mathrm{OH})_{2}{ }^{+} \cdot\left(\mathrm{H}_{2} \mathrm{O}\right)_{3}$

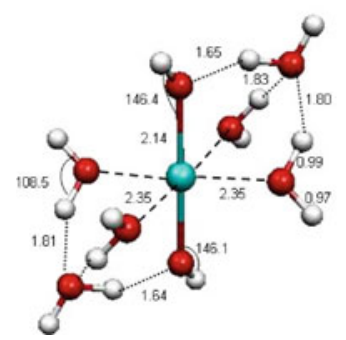

$\mathrm{Yb}(\mathrm{OH})_{2}{ }^{+} \cdot\left(\mathrm{H}_{2} \mathrm{O}\right)_{4}\left(\mathrm{H}_{2} \mathrm{O}\right)_{2}$

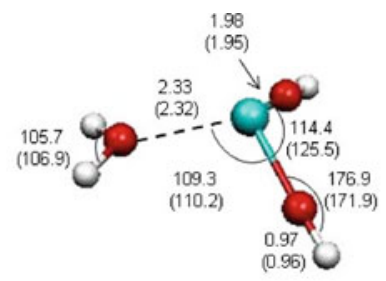

$\mathrm{Yb}(\mathrm{OH})_{2}{ }^{+} \cdot\left(\mathrm{H}_{2} \mathrm{O}\right)$

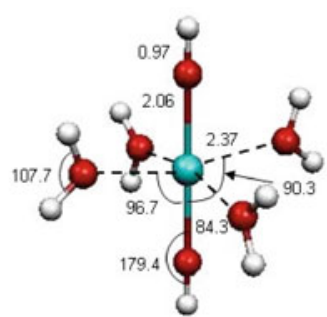

$\mathrm{Yb}(\mathrm{OH})_{2}{ }^{+} \cdot\left(\mathrm{H}_{2} \mathrm{O}\right)_{4}$

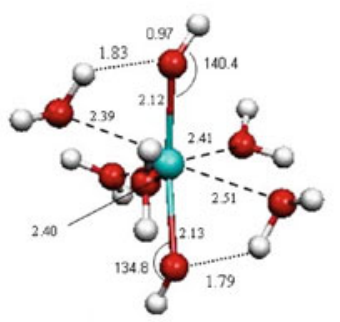

$\mathrm{Yb}(\mathrm{OH})_{2}{ }^{+} \cdot\left(\mathrm{H}_{2} \mathrm{O}\right)_{5}$

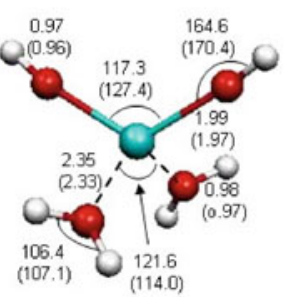

$\mathrm{Yb}(\mathrm{OH})_{2}{ }^{+} \cdot\left(\mathrm{H}_{2} \mathrm{O}\right)_{2}$

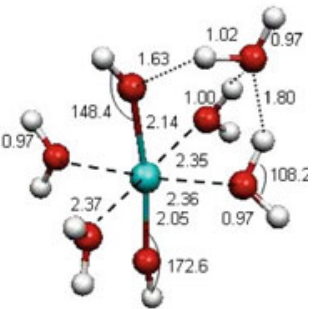

$\mathrm{Yb}(\mathrm{OH})_{2}{ }^{+} \cdot\left(\mathrm{H}_{2} \mathrm{O}\right)_{4}\left(\mathrm{H}_{2} \mathrm{O}\right)$

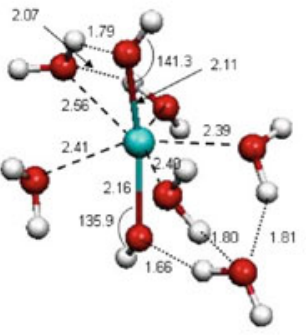

$\mathrm{Yb}(\mathrm{OH})_{2}{ }^{+} \cdot\left(\mathrm{H}_{2} \mathrm{O}\right)_{5}\left(\mathrm{H}_{2} \mathrm{O}\right)$
$\mathrm{Yb}(\mathrm{OH})_{2}^{+} \cdot\left(\mathrm{H}_{2} \mathrm{O}\right)$. The only exception is $\mathrm{YbF}_{2}^{+} \cdot\left(\mathrm{H}_{2} \mathrm{O}\right)$, in which the GS has a planar geometry that is only slightly more stable than a pyramidal isomer (relative energy, $\mathrm{RE}=12 \mathrm{~kJ} \mathrm{~mol}^{-1}$ ) at the PBE-ZORA/TZ2P level of theory. In contrast, the B3LYP/SDD-ANO level of theory clearly favors the pyramidal structure. At this level, the planar structure $\left(\mathrm{RE}=17 \mathrm{~kJ} \mathrm{~mol}^{-1}\right.$ ) is not a real minimum on the potential energy surface of the system. The addition of water induces a lengthening of the $\mathrm{Yb}-\mathrm{X}$ ( $\mathrm{X}=\mathrm{OH}, \mathrm{F}, \mathrm{Cl}$ ) bond, by between 0.01 and $0.06 \AA$, and an opening of the $\mathrm{X}-\mathrm{Yb}-\mathrm{X}$ or $\mathrm{X}-\mathrm{Yb}-\mathrm{OH}$ angle, by between 1 and 30 degrees.

The second hydration induces a further opening of the $\mathrm{X}-\mathrm{Yb}-\mathrm{X}$ or $\mathrm{X}-\mathrm{Yb}-\mathrm{OH}$ angle by no more than 5 degrees and a lengthening of the $\mathrm{Yb}-\mathrm{X}$ distances by no more than $0.2 \AA$. The $\mathrm{Yb}-\mathrm{OH}_{2}$ distances are in general slightly longer (by up to $0.03 \AA$ ) than the corresponding length in the monohydrates.

The $\mathrm{YbX}_{2}^{+}$and $\mathrm{YbX}(\mathrm{OH})^{+}$cations in the trihydrates show linear structures with an exception of $\mathrm{YbF}(\mathrm{OH})^{+}$, which is more distorted. The three water molecules are distributed fairly symmetrically, very close to a trigonal bipyramid structure. In the case of $\mathrm{YbF}(\mathrm{OH})^{+}$, two other isomers were located at the PBE-ZORA/TZ2P level of theory, which are almost degenerate in energy (within $5 \mathrm{~kJ} \mathrm{~mol}^{-1}$ ) and exhibit folded structures (Supporting Information, Figure S1).

The tetrahydrates are fairly symmetric with linear $\mathrm{YbX}_{2}{ }^{+}$and $\mathrm{YbX}(\mathrm{OH})^{+}$structures. The GS geometries are slightly distorted from a bipyramidal structure. However, the $\mathrm{YbF}(\mathrm{OH})^{+}$cation presents a more distorted geometry. In general, similar to the previous hydrations, the addition of a fourth water molecule lengthens the bond distances of all of the ligands.

For all of the studied cations, the lowest energy pentahydrates are obtained when the fifth water molecule is placed in the second coordination shell. The fifth water molecule forms two hydrogen bonds with two water molecules from the first coordination shell, and a third hydrogen bond is formed only with the fluoride and hydroxide ligands.

Pentahydrated $\mathrm{YbX}_{2}^{+} \cdot\left(\mathrm{H}_{2} \mathrm{O}\right)_{5}$ and $\mathrm{YbX}(\mathrm{OH})^{+} \cdot\left(\mathrm{H}_{2} \mathrm{O}\right)_{5}$ isomers of the $\mathrm{YbX}_{2}^{+} \cdot\left(\mathrm{H}_{2} \mathrm{O}\right)_{4}\left(\mathrm{H}_{2} \mathrm{O}\right)$ and $\mathrm{YbX}(\mathrm{OH})^{+} \cdot\left(\mathrm{H}_{2} \mathrm{O}\right)_{4}$ $\left(\mathrm{H}_{2} \mathrm{O}\right)$ GS structures were calculated to be, in all cases, 
Fig. 10 Lowest energy equilibrium structures for $\mathrm{YbF}_{2}{ }^{+} \cdot\left(\mathrm{H}_{2} \mathrm{O}\right)_{n}, n=0-6$. Distances $(\AA)$ and angles (degrees) are given. B3LYP/ SDD-ANO results are in parentheses. $\mathrm{YbF}_{2}{ }^{+} \cdot\left(\mathrm{H}_{2} \mathrm{O}\right)_{5}$ and $\mathrm{YbF}_{2}{ }^{+} \cdot\left(\mathrm{H}_{2} \mathrm{O}\right)_{5}\left(\mathrm{H}_{2} \mathrm{O}\right)$ are highenergy species. The relative energies of these latter species with respect to the ground state structures,

$\mathrm{YbF}_{2}^{+} \cdot\left(\mathrm{H}_{2} \mathrm{O}\right)_{4}\left(\mathrm{H}_{2} \mathrm{O}\right)$ and $\mathrm{YbF}_{2}+\cdot\left(\mathrm{H}_{2} \mathrm{O}\right)_{4}\left(\mathrm{H}_{2} \mathrm{O}\right)_{2}$, respectively, are 5 and $16 \mathrm{~kJ} \mathrm{~mol}^{-1}$. Italics denote water molecules in the second solvation shell

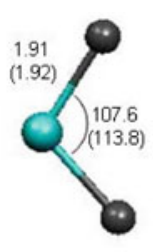

$\mathrm{YbF}_{2}^{+}$

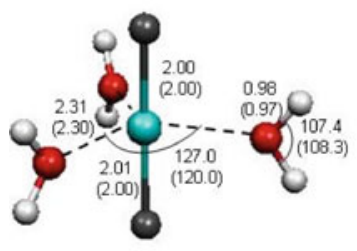

$\mathrm{YbF}_{2}^{+} \cdot\left(\mathrm{H}_{2} \mathrm{O}\right)_{3}$

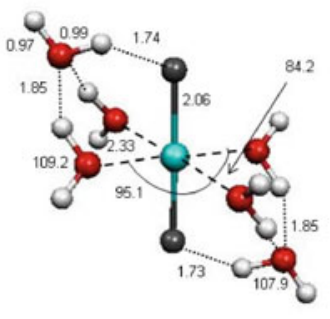

$\mathrm{YbF}_{2}^{+} \cdot\left(\mathrm{H}_{2} \mathrm{O}\right)_{4}\left(\mathrm{H}_{2} \mathrm{O}\right)_{2}$

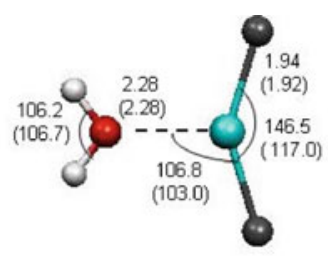

$\mathrm{YbF}_{2}^{+} \cdot\left(\mathrm{H}_{2} \mathrm{O}\right)$

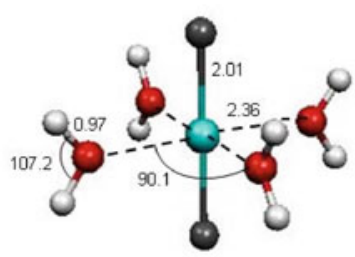

$\mathrm{YbF}_{2}^{+} \cdot\left(\mathrm{H}_{2} \mathrm{O}\right)_{4}$

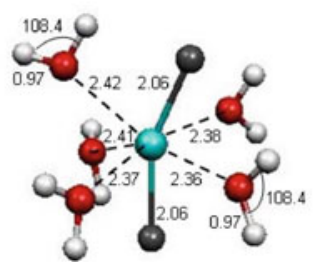

$\mathrm{YbF}_{2}{ }^{+} \cdot\left(\mathrm{H}_{2} \mathrm{O}\right)_{5}$

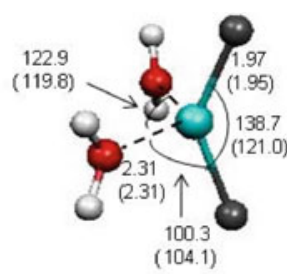

$\mathrm{YbF}_{2}^{+} \cdot\left(\mathrm{H}_{2} \mathrm{O}\right)_{2}$

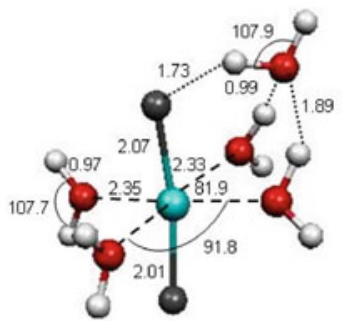

$\mathrm{YbF}_{2}^{+} \cdot\left(\mathrm{H}_{2} \mathrm{O}\right)_{4}\left(\mathrm{H}_{2} \mathrm{O}\right)$

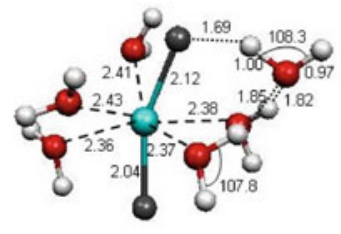

$\mathrm{YbF}_{2}^{+} \cdot\left(\mathrm{H}_{2} \mathrm{O}\right)_{5}\left(\mathrm{H}_{2} \mathrm{O}\right)$ between 3 and $20 \mathrm{~kJ} \mathrm{~mol}^{-1}$ higher in energy (see Figs. 9, $10,11,12,13)$. The addition of a fifth water molecule to the first coordination shell induces an expansion of the first shell with an average lengthening of the $\mathrm{Yb}-\mathrm{OH}_{2}$ bonds by $0.06 \AA$ up to $0.1 \AA$.

The lowest energy hexahydrated complexes are characterized by the presence of four water molecules in the first coordination shell and two in the second shell. The coordination geometries are fairly symmetric with the second-shell molecules forming two hydrogen bonds to different innersphere water molecules and, when possible, a third hydrogen bond is formed with a fluoride or hydroxide ligand. No stable structures with six water molecules in the first coordination shell were located. However, structures with five water molecules in the first shell and a sixth in the second shell were located and determined to be high energy in all cases (see Figs. 9, 10, 11, 12, 13).

Atomic charges calculated using AIM and NPA analyses for all of the bare and hydrated cations are summarized in tables S1 to S5 (Supporting Information). Both population analyses predict a decrease in the $\mathrm{YbX}_{2}{ }^{+}$and $\mathrm{YbX}(\mathrm{OH})^{+}$charges resulting from a partial charge transfer from the first coordination shell of water molecules to the complex. The amount of charge transferred to the $\mathrm{YbX}_{2}{ }^{+}$ or $\mathrm{YbX}(\mathrm{OH})^{+}$unit after adding the first four water molecules ranged from $0.29 \mathrm{e}^{-}$for $\mathrm{YbF}_{2}^{+}$to $0.19 \mathrm{e}^{-}$for $\mathrm{Yb}(\mathrm{OH})_{2}^{+}$. Therefore, the first solvation shell significantly stabilizes the charge of the cations through electron donation.

Clark and Kuta [16] have recently studied the trends in aqueous hydration of bare trivalent lanthanide cations and found that, in general, the addition of a second solvation shell induces a charge transfer from exterior to interior coordinated water molecules, which further decreases the charge on the metal by between 0.05 and $0.16 \mathrm{e}^{-}$. In this same study, which used a level of theory comparable to that used in this work, it was found that the NPA metal charge in $\mathrm{Yb}\left(\mathrm{H}_{2} \mathrm{O}\right)_{8}^{3+}$ is $1.786 \mathrm{au}$; on average, each water molecule donates $0.13 \mathrm{e}^{-}$to the metal center. In the case of the $\mathrm{YbX}_{2}^{+}$and $\mathrm{YbX}(\mathrm{OH})^{+}$cations studied here, the addition of the second shell of water molecules generally increases the positive charge of the core unit because of the direct interaction established between the second-shell water molecules and the $\mathrm{X}$ ligands. A more detailed discussion is included as Supporting Information.

\subsection{Hydration energies}

All of the studied biligated $\mathrm{Yb}$ cations are found to form stable hydrates. The reaction energies, enthalpies, 
Fig. 11 Lowest energy equilibrium structures for $\mathrm{YbF}(\mathrm{OH})^{+} \cdot\left(\mathrm{H}_{2} \mathrm{O}\right)_{n}, n=0-6$. Distances $(\AA)$ and angles (degrees) are given. B3LYP/ SDD-ANO results are in parentheses.

$\mathrm{YbF}(\mathrm{OH})^{+} \cdot\left(\mathrm{H}_{2} \mathrm{O}\right)_{5}$ and $\mathrm{YbF}(\mathrm{OH})^{+} \cdot\left(\mathrm{H}_{2} \mathrm{O}\right)_{5}\left(\mathrm{H}_{2} \mathrm{O}\right)$ are high-energy species. The relative energies of these latter species with respect to the ground state structures, $\mathrm{YbF}(\mathrm{OH})^{+} \cdot\left(\mathrm{H}_{2} \mathrm{O}\right)_{4}\left(\mathrm{H}_{2} \mathrm{O}\right)$ and $\mathrm{YbF}(\mathrm{OH})^{+} \cdot\left(\mathrm{H}_{2} \mathrm{O}\right)_{4}\left(\mathrm{H}_{2} \mathrm{O}\right)_{2}$, respectively, are 7 and $14 \mathrm{~kJ} \mathrm{~mol}^{-1}$. Italics denote water molecules in the second solvation shell
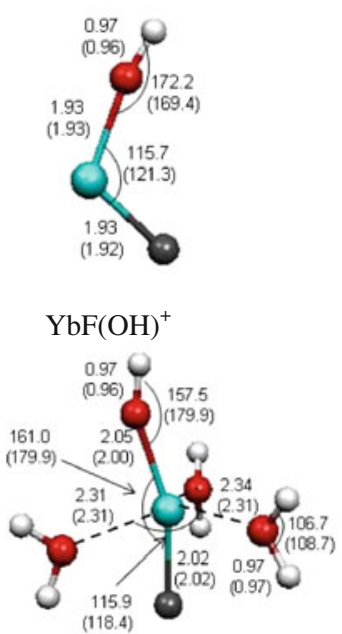

$\mathrm{YbF}(\mathrm{OH})^{+} \cdot\left(\mathrm{H}_{2} \mathrm{O}\right)_{3}$

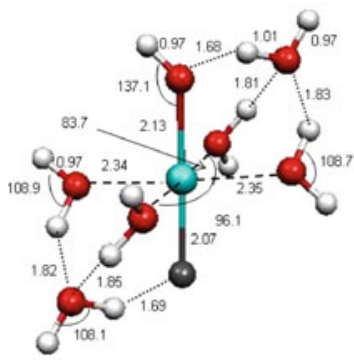

$\mathrm{YbF}(\mathrm{OH})^{+} \cdot\left(\mathrm{H}_{2} \mathrm{O}\right)_{4}\left(\mathrm{H}_{2} \mathrm{O}\right)_{2}$ entropies, and Gibbs free energies for all six hydrations are summarized in Table 4. The reactions are in all cases exothermic and show a monotonic decrease with the increase in the number of coordinated water molecules.

The first and second hydration energies are very similar for $\mathrm{Yb}(\mathrm{OH})_{2}^{+}, \mathrm{YbCl}_{2}{ }^{+}$, and $\mathrm{YbCl}(\mathrm{OH})^{+}$, whereas the second hydration is less exothermic than the first hydration for $\mathrm{YbF}_{2}{ }^{+}$and $\mathrm{YbF}(\mathrm{OH})^{+}$by about $20 \mathrm{~kJ} \mathrm{~mol}^{-1}$. For each of the studied cations, there is a substantial decrease in the exothermicity for the third hydration. That reduction ranges from $24 \mathrm{~kJ} \mathrm{~mol}^{-1}$ for $\mathrm{YbF}_{2}{ }^{+}$and $\mathrm{YbCl}_{2}{ }^{+}$to almost $60 \mathrm{~kJ} \mathrm{~mol}^{-1}$ for $\mathrm{Yb}(\mathrm{OH})_{2}^{+}$. Such a precipitous decrease in binding energy from $n=2$ to $n=3$ has been observed previously for many transition metal ions, as recently summarized by Cheng et al. [46, 47]: for example, the $\mathrm{Ti}^{+}\left(\mathrm{H}_{2} \mathrm{O}\right)_{n}$ binding energies (in $\mathrm{kJ} \mathrm{mol}^{-1}$ ) are $158 \pm 6$ for $n=1 ; 136 \pm 5$ for $n=2$; and $69 \pm 7$ for $n=3$.

The energies of hydration of all tetrahydrates are quite similar, ranging from 78 to $86 \mathrm{~kJ} \mathrm{~mol}^{-1}$. The energies involved for the addition of a fifth water molecule depends on the number of hydrogen bonds that are formed. When three hydrogen bonds are formed in a pentahydrate, which is the case for all of the cations except $\mathrm{YbCl}_{2}{ }^{+}$, the values range from 64 to $70 \mathrm{~kJ} \mathrm{~mol}^{-1}$. However, in the case of $\mathrm{YbCl}_{2}{ }^{+}$, only two hydrogen bonds are formed and the
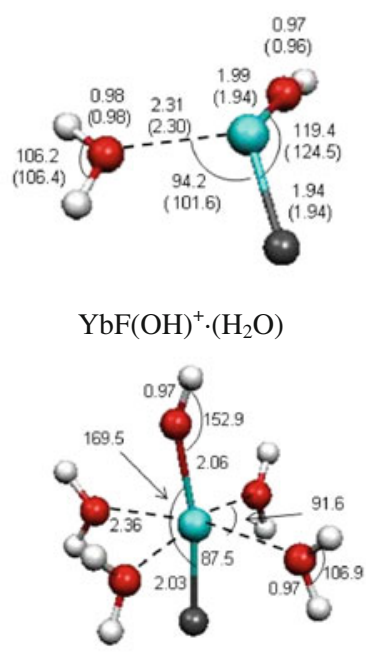

$\mathrm{YbF}(\mathrm{OH})^{+} \cdot\left(\mathrm{H}_{2} \mathrm{O}\right)_{4}$

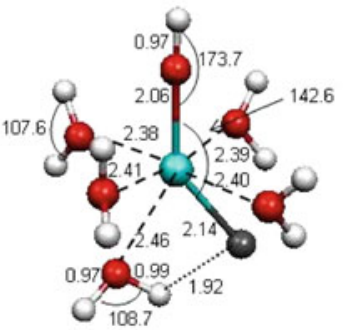

$\mathrm{YbF}(\mathrm{OH})^{+} \cdot\left(\mathrm{H}_{2} \mathrm{O}\right)_{5}$
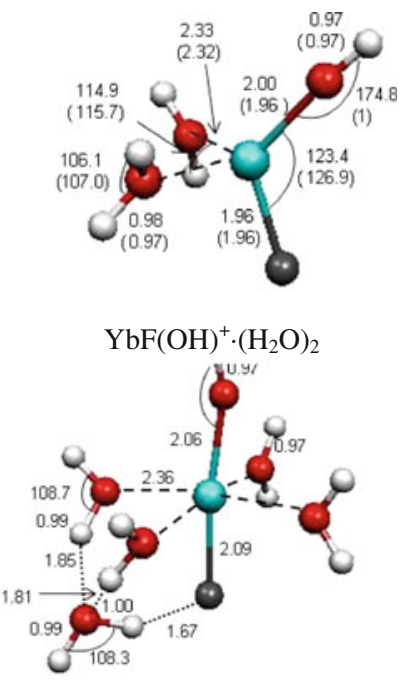

$\mathrm{YbF}(\mathrm{OH})^{+} \cdot\left(\mathrm{H}_{2} \mathrm{O}\right)_{4}\left(\mathrm{H}_{2} \mathrm{O}\right)$

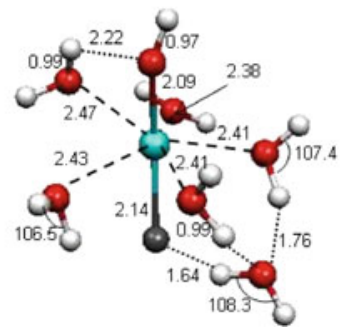

$\mathrm{YbF}(\mathrm{OH})^{+} \cdot\left(\mathrm{H}_{2} \mathrm{O}\right)_{5}\left(\mathrm{H}_{2} \mathrm{O}\right)$ exothermicity is only $60 \mathrm{~kJ} \mathrm{~mol}^{-1}$. The addition of the fifth water in the second shell is less exothermic than the addition of the fourth water molecule in the first shell by between 10 and $18 \mathrm{~kJ} \mathrm{~mol}^{-1}$. The only instance in which that difference is higher is for $\mathrm{YbCl}_{2}^{+}\left(26 \mathrm{~kJ} \mathrm{~mol}^{-1}\right)$, in which only two hydrogen bonds stabilize the fifth outersphere water.

The formation of hexahydrates involves hydration energies that are similar to those of pentahydrates (within $8 \mathrm{~kJ} \mathrm{~mol}^{-1}$ ), provided that the addition of the fifth and sixth water molecules involve the formation of an identical number of hydrogen bonds. For $\mathrm{YbCl}(\mathrm{OH})^{+}$, the fifth hydration forms three hydrogen bonds and the sixth forms only two resulting in an energetic difference of about $20 \mathrm{~kJ} \mathrm{~mol}^{-1}$.

A comparison between the energetic results obtained at the different levels of theory shows that the B3LYP/SDDANO level of theory gives hydration energies that are systematically between 7 and $39 \mathrm{~kJ} \mathrm{~mol}^{-1}$ more exothermic than those obtained using the PBE-ZORA/TZ2P approach. This difference is a combined effect of the different functional/basis sets and method (i.e., different ways of including the relativistic effects). As previously mentioned, there is also an important dependency of the optimized geometrical parameters with the size of the basis 
Fig. 12 Lowest energy equilibrium structures for $\mathrm{YbCl}_{2}{ }^{+} \cdot\left(\mathrm{H}_{2} \mathrm{O}\right)_{n}, n=0-6$. Distances ( $\mathrm{\AA})$ and angles (degrees) are given. B3LYP/ SDD-ANO results are in parentheses. $\mathrm{YbCl}_{2}{ }^{+} \cdot\left(\mathrm{H}_{2} \mathrm{O}\right)_{5}$ and $\mathrm{YbCl}_{2}{ }^{+} \cdot\left(\mathrm{H}_{2} \mathrm{O}\right)_{5}\left(\mathrm{H}_{2} \mathrm{O}\right)$ are high-energy species. The relative energies of these latter species with respect to the ground state structures, $\mathrm{YbCl}_{2}{ }^{+} \cdot\left(\mathrm{H}_{2} \mathrm{O}\right)_{4}\left(\mathrm{H}_{2} \mathrm{O}\right)$ and $\mathrm{YbCl}_{2}{ }^{+} \cdot\left(\mathrm{H}_{2} \mathrm{O}\right)_{4}\left(\mathrm{H}_{2} \mathrm{O}\right)_{2}$, respectively, are both $3 \mathrm{~kJ} \mathrm{~mol}^{-1}$. Italics denote water molecules in the second solvation shell

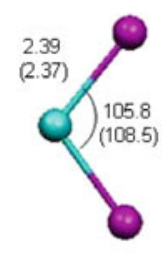

$\mathrm{YbCl}_{2}^{+}$

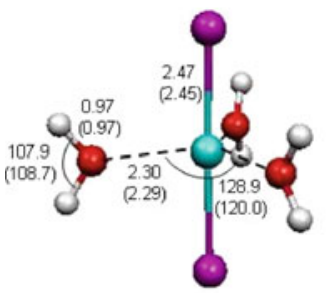

$\mathrm{YbCl}_{2}{ }^{+} \cdot\left(\mathrm{H}_{2} \mathrm{O}\right)_{3}$

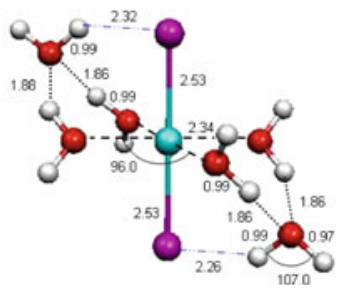

$\mathrm{YbCl}_{2}^{+} \cdot\left(\mathrm{H}_{2} \mathrm{O}\right)_{4}\left(\mathrm{H}_{2} \mathrm{O}\right)_{2}$

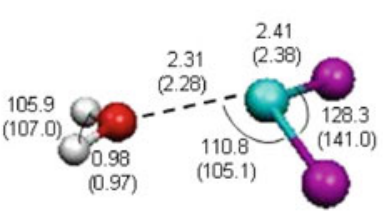

$\mathrm{YbCl}_{2}^{+} \cdot\left(\mathrm{H}_{2} \mathrm{O}\right)$

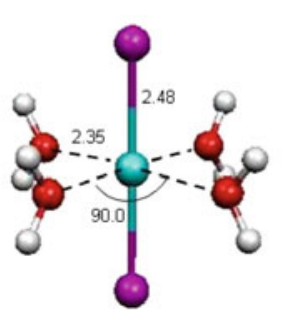

$\mathrm{YbCl}_{2}^{+} \cdot\left(\mathrm{H}_{2} \mathrm{O}\right)_{4}$

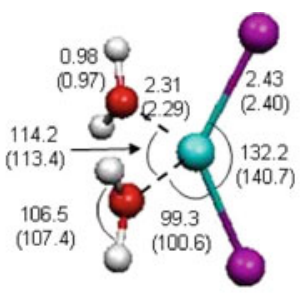

$\mathrm{YbCl}_{2}^{+} \cdot\left(\mathrm{H}_{2} \mathrm{O}\right)_{2}$

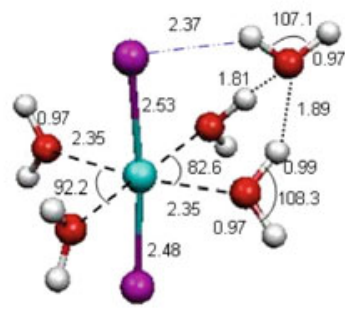

$\mathrm{YbCl}_{2}{ }^{+} \cdot\left(\mathrm{H}_{2} \mathrm{O}\right)_{4}\left(\mathrm{H}_{2} \mathrm{O}\right)$

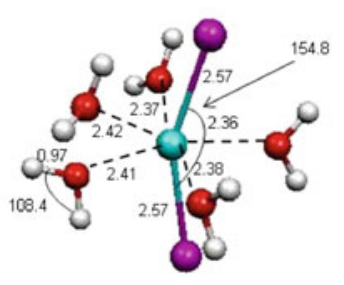

$\mathrm{YbCl}_{2}{ }^{+} \cdot\left(\mathrm{H}_{2} \mathrm{O}\right)_{5}$

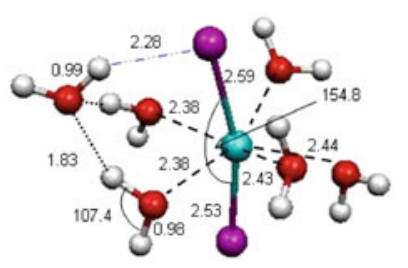

$\mathrm{YbCl}_{2}^{+} \cdot\left(\mathrm{H}_{2} \mathrm{O}\right)_{4}\left(\mathrm{H}_{2} \mathrm{O}\right)$ sets, which is particularly evident for the $\mathrm{X}-\mathrm{Yb}-\mathrm{X}$ and $\mathrm{X}-\mathrm{Yb}-\mathrm{OH}$ angles of the smallest systems (Sect. 3; Figs. 9, $10,11,12,13)$. Previous theoretical studies of the hydration of bare $\mathrm{Ce}^{3+}$ cations[18] have shown very good agreement between gas-phase hydration energies when using PW91, which is expected to behave similarly to the PBE functional used here, and B3LYP, when the two are used in combination with the same basis sets (double-zeta Stuttgart relativistic small-core potentials). In the systems studied here, however, the hydration process also induces a weakening of the $\mathrm{Yb}-\mathrm{X}$ and $\mathrm{Yb}-\mathrm{OH}$ bonds, which is revealed by the lengthening of the corresponding bond distances (Figs. 9, 10, 11, 12, 13), which will also influence the calculated hydration energy and are presumably accounted for in a different manner by the different density functionals. Some test calculations performed at the B3LYP-ZORA/TZ2P level (i.e., single-point calculations on the PBE-ZORA/TZ2P-optimized structures of $\mathrm{Yb}(\mathrm{OH})^{+}$ and its initial hydrates) do in fact give hydration energies that are very close to those calculated at B3LYP/SDDANO.

The entropy changes calculated for the first and second hydrations are similar. Those values range between -113 $(-114)$ and $-136(-124) \mathrm{J} \mathrm{K}^{-1} \mathrm{~mol}^{-1}$ for the first hydration at the PBE-ZORA/TZ2P (B3LYP/SDD-ANO) level of theory and between $-100(-117)$ and -132 $(-135) \mathrm{J} \mathrm{K}^{-1} \mathrm{~mol}^{-1}$ for the second hydration. There is an increase in the $\Delta \mathrm{S}$ values for the third hydration with values between $-126(-132)$ and $-156(-145) \mathrm{J} \mathrm{K}^{-1}$ $\mathrm{mol}^{-1}$ and a decrease for the fourth hydration with values between -112 and $-124 \mathrm{~J} \mathrm{~K}^{-1} \mathrm{~mol}^{-1}$. The addition of the fifth and sixth water molecule involves entropy changes that are much higher than those of the previous hydrations. Those values range between -154 and $-180 \mathrm{~J} \mathrm{~K}^{-1} \mathrm{~mol}^{-1}$ for the fifth hydration and between -164 and $-181 \mathrm{~J} \mathrm{~K}^{-1}$ $\mathrm{mol}^{-1}$ for the sixth hydration.

The hydration exoergicities, $\Delta \mathrm{G}^{298}$, are considered relevant to understanding the experimental observations and are included in Table 4. The trends are generally rather similar to those for the computed hydration energies and enthalpies, with a few exceptions. Among the more significant results is the value of $\Delta \mathrm{G}^{298}$ for the third hydration of $\mathrm{Yb}(\mathrm{OH})_{2}^{+}$, which is anomalously low at both levels of theory; it is notable that the corresponding $\Delta \mathrm{G}^{298}$ for the third hydration of $\mathrm{YbX}(\mathrm{OH})^{+}$is also significantly lower than for the $\mathrm{YbX}_{2}{ }^{+}$ions. Apparently, the hydroxide ligands destabilize the third hydrates in particular, due to both less favorable enthalpies and entropies. 
Fig. 13 Lowest energy equilibrium structures for $\mathrm{YbCl}(\mathrm{OH})^{+} \cdot\left(\mathrm{H}_{2} \mathrm{O}\right)_{n}, n=0-6$. Distances $(\AA)$ and angles (degrees) are given. B3LYP/ SDD-ANO results are in parentheses.

$\mathrm{YbCl}(\mathrm{OH})^{+} \cdot\left(\mathrm{H}_{2} \mathrm{O}\right)_{5}$ and $\mathrm{YbCl}(\mathrm{OH})^{+} \cdot\left(\mathrm{H}_{2} \mathrm{O}\right)_{5}\left(\mathrm{H}_{2} \mathrm{O}\right)$ are high-energy species. The relative energies of these latter species with respect to the ground state structures, $\mathrm{YbCl}(\mathrm{OH})^{+} \cdot\left(\mathrm{H}_{2} \mathrm{O}\right)_{4}\left(\mathrm{H}_{2} \mathrm{O}\right)$ and $\mathrm{YbCl}(\mathrm{OH})^{+} \cdot\left(\mathrm{H}_{2} \mathrm{O}\right)_{4}\left(\mathrm{H}_{2} \mathrm{O}\right)_{2}$, respectively, are 17 and $6 \mathrm{~kJ} \mathrm{~mol}^{-1}$. Italics denote water molecules in the second solvation shell
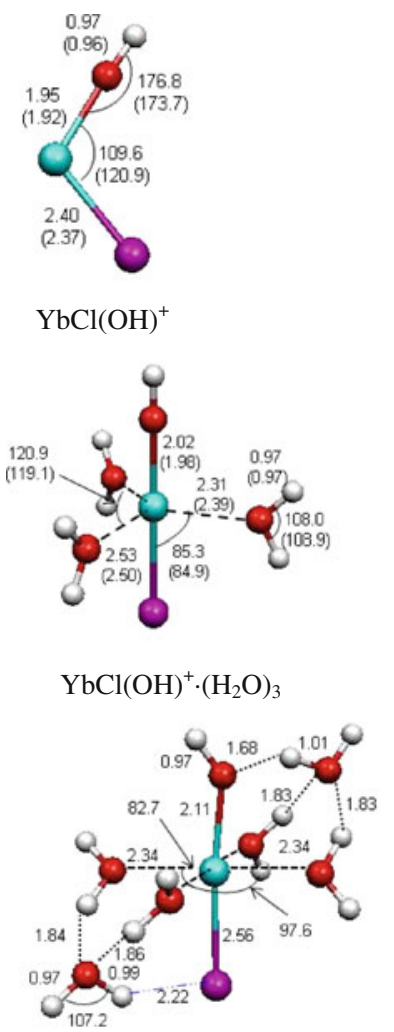

$\mathrm{YbCl}(\mathrm{OH})^{+} \cdot\left(\mathrm{H}_{2} \mathrm{O}\right)_{4}\left(\mathrm{H}_{2} \mathrm{O}\right)_{2}$
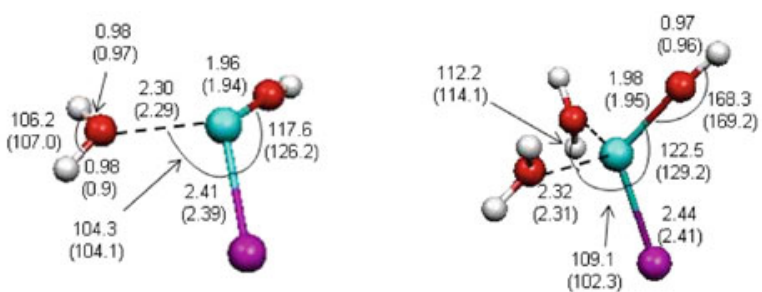

$\mathrm{YbCl}(\mathrm{OH})^{+} \cdot\left(\mathrm{H}_{2} \mathrm{O}\right)$

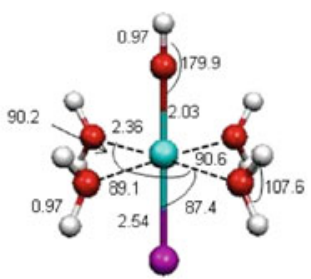

$$
\mathrm{YbCl}(\mathrm{OH})^{+} \cdot\left(\mathrm{H}_{2} \mathrm{O}\right)_{4}
$$

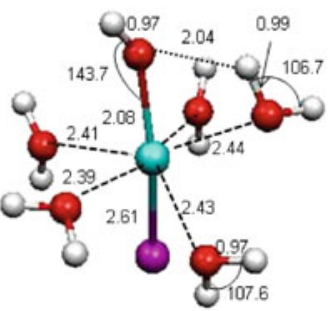

$\mathrm{YbCl}(\mathrm{OH})^{+} \cdot\left(\mathrm{H}_{2} \mathrm{O}\right)_{5}$
$\mathrm{YbCl}(\mathrm{OH})^{+} \cdot\left(\mathrm{H}_{2} \mathrm{O}\right)_{4}\left(\mathrm{H}_{2} \mathrm{O}\right)$

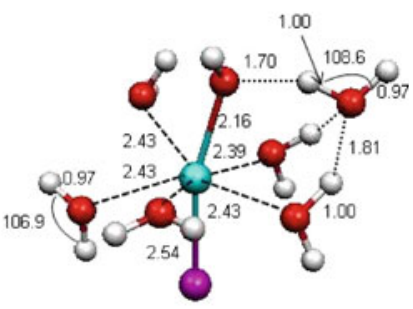

$\mathrm{YbCl}(\mathrm{OH})^{+} \cdot\left(\mathrm{H}_{2} \mathrm{O}\right)_{5}\left(\mathrm{H}_{2} \mathrm{O}\right)$

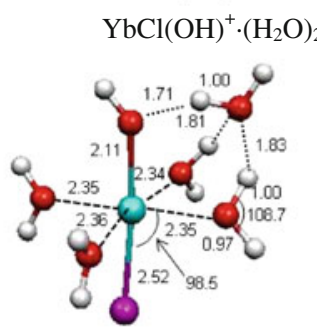

\section{Experimental observations in relation to theory}

\subsection{Hydration kinetics}

A central goal of this work is to explore the relationship between gas-phase hydration and computed hydration energetics and hydrate structures. Observed gas-phase hydration kinetics are determined by both thermodynamics-i.e., the driving force for the association reactions - and mechanistics-i.e., barriers to hydration and/or dissociation of the nascent association complexes. Among the particularly intriguing aspects of the measured hydration kinetics is the observation that the first hydration step is invariably slower than the second (Fig. 7). The experiment and theory results can be directly compared for the particular cases of the first and second hydrations of $\mathrm{Yb}(\mathrm{OH})_{2}^{+}$and $\mathrm{YbCl}(\mathrm{OH})^{+}$. For both of these species, the second hydration is significantly more efficient than the first hydration (Table 1). Referring to the computed energetics for these hydrations (Table 4), the first hydration is more energetically favorable, as evaluated by both exothermicity $(\Delta \mathrm{H})$ and exoergicity $(\Delta \mathrm{G})$. Similar results-slower first addition than second addition-were reported and rationalized by Bohme and co-workers for $\mathrm{NH}_{3}$ and $\mathrm{D}_{2} \mathrm{O}$ association with bare metal cations [47-49].
Association of a water molecule to a species such as $\mathrm{Yb}(\mathrm{OH})_{2}^{+}$should be essentially barrierless, with the water molecule binding to the exposed metal center, as in $\mathrm{Yb}(\mathrm{OH})_{2}^{+}$in Fig. 9. Accordingly, the relatively inefficient first hydration is attributed to the efficient dissociation of the excited-state monohydrate, a process that is similarly barrierless. For the hydrate to survive, it must be cooled by third-body collisions with the He bath gas before dissociation. To confirm collisional stabilization of association complexes under our experimental conditions, the $\mathrm{He}$ pressure dependence of the first hydration rate of $\mathrm{UO}_{2}(\mathrm{OH})^{+}$was examined at constant water pressure. We used the $\mathrm{UO}_{2}(\mathrm{OH})^{+}$ion employed for confirming the constancy of water pressure in the trap; it should exhibit similar association complex cooling behavior as the studied lanthanide complex ions. The hydration rate decreased by $\sim 50 \%$ when the He pressure was halved, increased by $\sim 30 \%$ when the He pressure was doubled, and decreased to $\sim 2 \%$ in the absence of He. The hot nascent hydrate complex is stabilized against prompt dissociation by dissipation of energy into internal modes of freedom, particularly vibrations: the greater and more accessible the vibrational degrees of freedom in the association complex, the greater the probability of its survival until collisional cooling. Our interpretation of the observed kinetics is that 
Table 4 Energy, enthalpy, entropy, and Gibbs free energy changes for the hydration reactions at the PBE-ZORA/TZ2P and the B3LYP/SDDANO levels of theory

\begin{tabular}{|c|c|c|c|c|c|}
\hline Reaction & $\mathrm{Yb}(\mathrm{OH})_{2}^{+}$ & $\mathrm{YbCl}_{2}^{+}$ & $\mathrm{YbCl}(\mathrm{OH})^{+}$ & $\mathrm{YbF}_{2}^{+}$ & $\mathrm{YbF}(\mathrm{OH})^{+}$ \\
\hline \multicolumn{6}{|l|}{$n=1$} \\
\hline$\Delta \mathrm{E}^{0}$ & $-132(-157)$ & $-146(-185)$ & $-135(-170)$ & $-165(-186)$ & $-148(-170)$ \\
\hline$\Delta \mathrm{H}^{298}$ & $-133(-159)$ & $-147(-188)$ & $-137(-172)$ & $-175(-188)$ & $-148(-172)$ \\
\hline$\Delta \mathrm{S}^{298}$ & $-123(-119)$ & $-113(-114)$ & $-136(-123)$ & $-126(-124)$ & $-117(-123)$ \\
\hline$\Delta \mathrm{G}^{298}$ & $-96(-124)$ & $-113(-154)$ & $-96(-135)$ & $-137(-151)$ & $-113(-135)$ \\
\hline \multicolumn{6}{|l|}{$n=2$} \\
\hline$\Delta \mathrm{E}^{0}$ & $-130(-143)$ & $-139(-163)$ & $-129(-155)$ & $-144(-165)$ & $-128(-153)$ \\
\hline$\Delta \mathrm{H}^{298}$ & $-128(-144)$ & $-140(-165)$ & $-130(-156)$ & $-145(-167)$ & $-129(-157)$ \\
\hline$\Delta \mathrm{S}^{298}$ & $-100(-117)$ & $-132(-135)$ & $-129(-127)$ & $-125(-121)$ & $-124(-122)$ \\
\hline$\Delta \mathrm{G}^{298}$ & $-98(-109)$ & $-101(-125)$ & $-92(-118)$ & $-108(-131)$ & $-92(-121)$ \\
\hline \multicolumn{6}{|l|}{$n=3$} \\
\hline$\Delta \mathrm{E}^{0}$ & $-71(-93)$ & $-114(-139)$ & $-93(-116)$ & $-119(-126)$ & $-89(-111)$ \\
\hline$\Delta \mathrm{H}^{298}$ & $-75(-96)$ & $-116(-143)$ & $-95(-119)$ & $-121(-129)$ & $-92(-111)$ \\
\hline$\Delta \mathrm{S}^{298}$ & $-156(-145)$ & $-131(-145)$ & $-131(-142)$ & $-126(-132)$ & $-151(-136)$ \\
\hline$\Delta \mathrm{G}^{298}$ & $-29(-53)$ & $-77(-100)$ & $-56(-77)$ & $-84(-90)$ & $-47(-70)$ \\
\hline \multicolumn{6}{|l|}{$n=4$} \\
\hline$\Delta \mathrm{E}^{0}$ & -75 & -86 & -86 & -83 & -78 \\
\hline$\Delta \mathrm{H}^{298}$ & -74 & -85 & -85 & -83 & -77 \\
\hline$\Delta \mathrm{S}^{298}$ & -115 & -124 & -121 & -122 & -112 \\
\hline$\Delta \mathrm{G}^{298}$ & -39 & -48 & -49 & -47 & -44 \\
\hline \multicolumn{6}{|l|}{$n=5$} \\
\hline$\Delta \mathrm{E}^{0}$ & -65 & -60 & -70 & -65 & -64 \\
\hline$\Delta \mathrm{H}^{298}$ & -72 & -65 & -77 & -71 & -71 \\
\hline$\Delta \mathrm{S}^{298}$ & -180 & -154 & -178 & -170 & -172 \\
\hline$\Delta \mathrm{G}^{298}$ & -18 & -19 & -24 & -24 & -20 \\
\hline \multicolumn{6}{|l|}{$n=5^{*}$} \\
\hline$\Delta \mathrm{E}^{0}$ & -39 & -57 & -53 & -60 & -58 \\
\hline$\Delta \mathrm{H}^{298}$ & -45 & -62 & -55 & -64 & -61 \\
\hline$\Delta \mathrm{S}^{298}$ & -169 & -164 & -145 & -155 & -148 \\
\hline$\Delta \mathrm{G}^{298}$ & 5 & -13 & -12 & -18 & -17 \\
\hline \multicolumn{6}{|l|}{$n=6$} \\
\hline$\Delta \mathrm{E}^{0}$ & -62 & -52 & -49 & -61 & -63 \\
\hline$\Delta \mathrm{H}^{298}$ & -68 & -60 & -56 & -66 & -70 \\
\hline$\Delta S^{298}$ & -171 & -164 & -181 & -165 & -174 \\
\hline$\Delta \mathrm{G}^{298}$ & -17 & -11 & -6 & -17 & -18 \\
\hline
\end{tabular}

The B3LYP/SDD-ANO level of theory is represented in parentheses. $\Delta \mathrm{E}^{0}, \Delta \mathrm{G}^{298}$, and $\Delta \mathrm{H}^{298}$ are in kJ.mol ${ }^{-1}$ and $\Delta \mathrm{S}^{298}$ is in J K $\mathrm{Kol}^{-1}$. The reactions correspond to successive hydrations: $\mathrm{YbX}_{2}^{+} \cdot\left(\mathrm{H}_{2} \mathrm{O}\right)_{n-1}+\mathrm{H}_{2} \mathrm{O} \rightarrow \mathrm{YbX}_{2}^{+} \cdot\left(\mathrm{H}_{2} \mathrm{O}\right)_{n}$ or $\mathrm{YbX}(\mathrm{OH})^{+} \cdot\left(\mathrm{H}_{2} \mathrm{O}\right)_{n-1}+\mathrm{H}_{2} \mathrm{O} \rightarrow \mathrm{YbX}(\mathrm{OH})^{+}$. $\left(\mathrm{H}_{2} \mathrm{O}\right)_{n}$. All of the reactants and products are in their ground state; therefore, the fifth and sixth water molecules are in the second coordination sphere. However, the pentahydrate complexes with five inner-sphere water molecules are included for comparison and are denoted as $n=5^{*}$

the first hydrates of $\mathrm{Yb}(\mathrm{OH})_{2}^{+}$(and the other biligated ions) are prone to promptly dissociate when compared with the second hydrates due to the lesser ligation and associated degrees of freedom for energy dissipation. This interpretation is consistent with the non-observation of hydration for the monoligated ions, $\mathrm{YbX}^{+}(\mathrm{X}=\mathrm{OH}, \mathrm{Cl}, \mathrm{Br}, \mathrm{I})$, which possess fewer vibrational modes when compared with the biligated ions. The gas-phase hydration of the $\mathrm{YbI}^{+} \cdot\left(\mathrm{H}_{2} \mathrm{O}\right)_{1-3}$ complexes produced by ESI is attributed to the degrees of freedom introduced by the coordinated water molecule. In the $\mathrm{NH}_{3}$ and $\mathrm{D}_{2} \mathrm{O}$ association reactions mentioned earlier [47-49], the observation that the first associations were slower than the second for bare metal cations was similarly attributed to the fewer degrees of 
freedom for energy dissipation in the first association. It is intriguing that the first hydration of $\mathrm{YbBr}(\mathrm{OH})^{+}$is slower than that of both $\mathrm{YbCl}(\mathrm{OH})^{+}$and $\mathrm{YbI}(\mathrm{OH})^{+}$. Such an apparent discontinuity down the halide series was not expected; however, analogously unique behavior of bromide has been reported in related systems. In particular, Anbalagan et al. [50] found that the CID behavior of $\mathrm{UO}_{2} \mathrm{Br}^{+} \cdot\left(\mathrm{H}_{2} \mathrm{O}\right)_{3}$ was very distinctive from that of $\mathrm{UO}_{2} \mathrm{Cl}^{+} \cdot\left(\mathrm{H}_{2} \mathrm{O}\right)_{3}$ and $\mathrm{UO}_{2} \mathrm{I}^{+} \cdot\left(\mathrm{H}_{2} \mathrm{O}\right)_{3}$.

The third hydration is slower than the second even though there are more vibrational degrees of freedom in the dihydrate than in the monohydrate complexes. The slower kinetics can be attributed to a large decrease in binding energy for the formation of the trihydrates. The calculated binding energies (and $\Delta \mathrm{G}$ ) for all biligated $\mathrm{Yb}$ cations (Table 4) decrease considerably for the third hydration. A direct correlation between experimental and calculated results can be made for $\mathrm{Yb}(\mathrm{OH})_{2}^{+}$and $\mathrm{YbCl}(\mathrm{OH})^{+}$; the reaction rates and binding energies for the third hydration decreased for both cations. In studies of $\mathrm{NH}_{3}$ coordination reactions of $\mathrm{Mg}^{+}, \mathrm{Fe}^{+}$, and $\mathrm{Ag}^{+}$by Bohme and co-workers, the third association reactions also exhibited slower kinetics than the second association reactions; this trend was attributed to the decrease in binding energies [48, 49]; we adopt this convincing interpretation to understand the trends observed in our hydration kinetics. Referring to Table 4, it is notable that the entropy change for the third hydration of $\mathrm{Yb}(\mathrm{OH})_{2}^{+}$is larger than for the other ions, resulting in a drastic increase in $\Delta \mathrm{G}^{298}$ between the second and third hydrations. The observation that the decrease in rates from the second to third hydrations is somewhat larger for $\mathrm{Yb}(\mathrm{OH})_{2}^{+}$(see Table 1) may reflect the particularly unfavorable entropy for this hydration.

The fourth hydrations of $\mathrm{Yb}(\mathrm{OH})_{2}^{+}$and $\mathrm{Tm}(\mathrm{OH})_{2}^{+}$ (Figs. 1, 9; Table 2) are very slow. As seen in Table 4, the energetics for this fourth hydration are quite favorable: the binding energies for the third and fourth water molecules, as indicated by both $\Delta \mathrm{H}^{298}$ and $\Delta \mathrm{G}^{298}$, are comparable within the accuracy of the computations. Furthermore, the presence of three coordinating water molecules in the reactant ion provides ample degrees of freedom to dissipate the hot hydrate prior to collisional cooling. Given the similar energetics for the third and fourth hydrations, the very slow kinetics for the latter can be attributed to greater steric crowding for the trihydrate when compared with the dihydrate (Fig. 9), which results in greater resistance to insertion of the fourth water molecule.

The first hydration for $\mathrm{Yb}(\mathrm{OH})_{2}^{+}$is slower than for $\mathrm{YbCl}(\mathrm{OH})^{+}$; the computed energetics for these hydrations, both $\Delta \mathrm{H}^{298}$ and $\Delta \mathrm{G}^{298}$, are very similar. The computed vibrational frequencies for the $\mathrm{Yb}(\mathrm{OH})_{2}^{+}$and $\mathrm{YbCl}(\mathrm{OH})^{+}$ bare cations are given in Table 5. The $\mathrm{Yb}-\mathrm{O}$ stretching frequency for $\mathrm{YbCl}(\mathrm{OH})^{+}$was calculated as $\sim 100 \mathrm{~cm}^{-1}$ lower than the same vibrational frequency for $\mathrm{Yb}(\mathrm{OH})_{2}^{+}$. The $\mathrm{Yb}-\mathrm{Cl}$ stretching frequency is much lower than the $\mathrm{Yb}-\mathrm{O}$ stretch, by $\sim 300 \mathrm{~cm}^{-1}$ in $\mathrm{YbCl}(\mathrm{OH})^{+}$. The $\mathrm{O}-\mathrm{H}$ stretching frequency was calculated to be much higher, at $\sim 3800 \mathrm{~cm}^{-1}$ in both bare cations. The lower frequency $\mathrm{Yb}-\mathrm{Cl}$ stretch would allow the bare $\mathrm{YbCl}(\mathrm{OH})^{+}$to dissipate the energy of hydration more efficiently in the vibrational modes of the "floppy" $\mathrm{Yb}-\mathrm{Cl}$ bond, resulting in a faster hydration rate when compared with $\mathrm{Yb}(\mathrm{OH})_{2}^{+}$due to stabilization of the nascent hot hydrate by internal dissipation of the excess energy.

\subsection{Absence of pentahydrates}

Calculations show that the heats of formation for the pentahydrate $\mathrm{Yb}$ complexes are exothermic. The experimental results for the first four hydrates have been primarily evaluated in the context of the computed energies (enthalpies) of hydration; for these hydrates, the computed $\Delta \mathrm{G}^{298}$ values are less favorable due to the entropy of association, but predict the observed hydration. A key issue is whether the exothermicity, $\Delta H^{298}$, or the exoergicity, $\Delta \mathrm{G}^{298}$, should be considered in the evaluation of gas-phase reactions [51]. At very low pressures (e.g., $<10^{-6}$ Torr) where third-body collisions are rare and reactions are bimolecular, the role of entropy is uncertain, particularly as it is problematic to define the "temperature" of such an isolated reaction system. At higher pressures, such as $\sim 10^{-4}$ Torr in the experiments reported here, it is clear that third-body collisions are crucial to stabilize the hydration product and the reactions are apparently bimolecular, such that the concepts of temperature (i.e., $T \approx 298 \mathrm{~K}$ ), entropy, and Gibbs free energy are more clearly relevant. The demonstration of the formation of a pentahydrate at relatively high water pressure-but not for long reaction times at lower pressure - suggests an approach to equilibrium conditions and thus the necessity for the consideration of $\Delta \mathrm{G}^{298}$.

It is seen from the values in Table 4 that whereas the $\Delta \mathrm{H}^{298}$ values decrease only modestly between the fourth and fifth hydration, the $\Delta \mathrm{G}^{298}$ values for the fifth hydrations become substantially less favorable than for the first

Table $5 \mathrm{Yb}(\mathrm{OH})_{2}^{+}$and $\mathrm{YbCl}(\mathrm{OH})^{+}$stretching frequencies computed at the PBE-ZORA/TZ2P and B3LYP/SDD-ANO levels of theory

\begin{tabular}{llc}
\hline Stretch & $\mathrm{Yb}(\mathrm{OH})_{2}^{+}$ & $\mathrm{YbCl}(\mathrm{OH})^{+}$ \\
\hline $\mathrm{Yb}-\mathrm{O}$ & $696(688)$ symmetric & $587(680)$ \\
& $662(676)$ asymmetric & \\
$\mathrm{Yb}-\mathrm{Cl}$ & - & $302(362)$ \\
$\mathrm{O}-\mathrm{H}$ & $3769(3908)$ symmetric & $3756(3877)$ \\
& $3758(3902)$ asymmetric & \\
\hline
\end{tabular}

The B3LYP/SDD-ANO level of theory is represented in parentheses. Stretching frequencies are given in $\mathrm{cm}^{-1}$ 
four hydrations, which may explain the absence of pentahydrates under our standard experimental conditions: no pentahydrate species were detected in mass spectra with the background water pressure despite that $\Delta \mathrm{G}^{298}$ is favorable, albeit by only $\sim 20 \mathrm{~kJ} \mathrm{~mol}^{-1}$. Calculations also show that, for all complexes, the lowest energy pentahydrate geometries contain four water molecules in the first coordination shell and one water molecule in the second coordination shell. Following the logic of Bohme and coworkers [47], the distinct decrease in binding of the fifth water molecules can be attributed to "a change in the nature of the bonding from direct bonding to hydrogen bonding in a second coordination shell". The water pressure in the ion trap is evidently adequately low to favor dehydration over second-shell hydration. A hydrated monopositive ion that undergoes second-shell hydration is somewhat similar to addition of water to a microdroplet in the gas phase; the positive charge and the ordered orientation of the inner-sphere water molecules distort from this simplistic scenario, but the very large decrease in $\Delta \mathrm{G}^{298}$ between the four inner-sphere and the fifth and sixth outersphere hydrations (Table 4) is consistent with this picture. At a water pressure of $\sim 10^{-6}$ Torr and a temperature of $298 \mathrm{~K}$, growth of water droplets, even nanodroplets, is unfavorable. It is feasible that inefficiently formed innershell pentahydrates might be observed at reaction times longer than $10 \mathrm{~s}$.

A minor amount of the pentahydrate of $\mathrm{Yb}(\mathrm{OH})_{2}^{+}$was seen when the water pressure in the ion trap was increased by an order of magnitude, with a reaction time of only $200 \mathrm{~ms}$. In contrast, increasing the reaction time by an order of magnitude at the lower (background) water pressure does not produce the pentahydrate. This is in accord with the proposition that it is the equilibrium in Eq. 5 which determines whether or not this outer-shell fifth hydrate is observed.

$\mathrm{Yb}(\mathrm{OH})_{2}^{+} \cdot\left(\mathrm{H}_{2} \mathrm{O}\right)_{4}+\mathrm{H}_{2} \mathrm{O} \leftrightarrow \mathrm{Yb}(\mathrm{OH})_{2}^{+} \cdot\left(\mathrm{H}_{2} \mathrm{O}\right)_{4}\left(\mathrm{H}_{2} \mathrm{O}\right)$

\section{Conclusions}

Hydration for the gas-phase $\mathrm{YbX}_{2}^{+}$and $\mathrm{YbX}(\mathrm{OH})^{+}$ $(\mathrm{X}=\mathrm{OH}, \mathrm{Cl}, \mathrm{Br}, \mathrm{I})$ cations terminated at four water molecules. No pentahydrate complexes were observed, except for a $\mathrm{Yb}(\mathrm{OH})_{2}^{+}$pentahydrate detected only with an order of magnitude increase in water pressure in the ion trap. DFT calculations show that the formation of $\mathrm{YbX}_{2}{ }^{+}$ and $\mathrm{YbX}(\mathrm{OH})^{+}$hydrates $(\mathrm{X}=\mathrm{OH}, \mathrm{F}, \mathrm{Cl})$ are all exothermic; computations were performed for monohydrates to hexahydrates. The calculations indicate that for the cations studied, pentahydrates with four inner-shell water molecules and one outer-shell water molecule are energetically more favorable than pentahydrates with five inner-shell water molecules. The absence of outer-sphere pentahydrates is in accord with previous studies by Bohme and co-workers [47-49] and can be attributed to rapid dehydration of the outer-sphere water molecule and a steric hindrance to addition of a fifth inner-shell water molecule.

Hydration kinetics were determined by isolating selected ions and allowing reactions with $\sim 10^{-6}$ Torr water in the ion trap for variable times. The general ordering of hydration rates for the biligated cations was 1 st $<$ 2nd $>3$ rd $>4$ th $(\gg 5$ th). The computed energetics do not fully account for this ordering and we invoke the rationale put forth by Bohme and co-workers [47-49]: the first hydration is inefficient due to fragmentation of the hot association complex with few degrees of freedom; the efficiencies of subsequent hydrations are dominated by the binding energies; the great inefficiency of the fifth hydration reflects a shift to outer-shell coordination.

Acknowledgments This work was supported by the Director, Office of Science, Office of Basic Energy Sciences, Division of Chemical Sciences, Geosciences and Biosciences of the U.S. Department of Energy at LBNL, under Contract No. DE-AC02-05CH11231, and by the Universitá della Calabria. M.C.M. is grateful for the opportunity to be a Guest Scientist in the Chemical Sciences Division at LBNL. J.M. is indebted to the Chemical Sciences Division of LBNL for the opportunity to visit the Berkeley laboratory in the summer of 2009. The CINECA supercomputing centre (Casalecchio di Reno, Italy) is acknowledged for the computational time.

Open Access This article is distributed under the terms of the Creative Commons Attribution Noncommercial License which permits any noncommercial use, distribution, and reproduction in any medium, provided the original author(s) and source are credited.

\section{References}

1. Habenschuss A, Spedding FH (1979) J Chem Phys 70:2797-2806

2. Habenschuss A, Spedding FH (1979) J Chem Phys 70:3758-3763

3. Habenschuss A, Spedding FH (1980) J Chem Phys 73:442-450

4. Beudert R, Bertagnolli H, Zeller M (1997) J Chem Phys 106:8841-8848

5. Yaita T, Ito D, Tachimori S (1998) J Phys Chem B 102:3886-3891

6. Biggin S, Enderby JE, Hahn RL, Narten AH (1984) J Phys Chem 88:3634-3638

7. Annis BK, Hahn RL, Narten AH (1985) J Chem Phys 82:2086-2091

8. Steele ML, Wertz DL (1976) J Am Chem Soc 98:4424-4428

9. Steele ML, Wertz DL (1977) Inorg Chem 16:1225-1228

10. Johansson G, Yokoyama H (1990) Inorg Chem 29:2460-2466

11. Duvail M, Spezia R, Vitorge P (2008) Chem Phys Chem 9:693-696

12. Villa A, Hess B, Saint-Martin H (2009) J Phys Chem B 113:7270-7281

13. Chaussedent S, Monteil A (1996) J Chem Phys 105:6532-6537

14. Floris FM, Tani A (2001) J Chem Phys 115:4750-4765 
15. Hughes SR, Nguyen T-N, Capobianco JA, Peslherbe GH (2005) Int J Mass Spectrom 241:283-294

16. Kuta J, Clark AE (2010) Inorg Chem 49:7808-7817

17. Buzko V, Sukhno I, Buzko M (2007) Int J Quantum Chem 107:2353-2360

18. Dinescu A, Clark AE (2008) J Phys Chem A 112:11198-11206

19. Clavaguéra C, Dognon J-P, Pyykkö P (2006) Chem Phys Lett 429:8-12

20. Lottermoser BG (1992) Ore Geol Rev 7:25-41

21. Migdisov AA, Williams-Jones AE, Wagner T (2009) Geochim Cosmochim Ac 73:7087-7109

22. Mayanovic RA, Jayanetti S, Anderson AJ, Bassett WA, Chou I-M (2002) J Phys Chem A 106:6591-6599

23. Mayanovic RA, Anderson AJ, Bassett WA, Chou I-M (2007) Chem Geol 239:266-283

24. Mayanovic RA, Anderson AJ, Bassett WA, Chou I-M (2009) Chem Geol 259:30-38

25. Gronert S (1998) J Am Soc Mass Spectrom 9:845-848

26. Van Stipdonk MJ, Chien W, Bulleigh K, Wu Q, Groenewold GS (2006) J Phys Chem A 110:959-970

27. Su T, Chesnavich WJ (1982) J Chem Phys 76:5183-5185

28. Perdew JP, Burke K, Ernzerhof M (1996) Phys Rev Lett 77:3865-3868

29. Perdew JP, Burke K, Ernzerhof M (1997) Phys Rev Lett 78:1396

30. ADF2004.01 SCM; Theoretical Chemistry, V. U., Amsterdam, The Netherlands, http://www.scm.com

31. Fonseca Guerra C, Snijders JG, te Velde G, Baerends EJ (1998) Theor Chem Acc 99:391-403

32. te Velde G, Bickelhaupt FM, van Gisbergen SJA, Fonseca Guerra C, Baerends EJ, Snijders JG, Ziegler T (2001) J Comput Chem 22:931-967

33. Becke AD (1993) J Chem Phys 98:5648-5652
34. Lee CT, Yang WT, Parr RG (1988) Phys Rev B 37:785-789

35. Dolg M, Stoll H, Preuss H (1989) J Chem Phys 90(3):1730-1734

36. Cao XY, Dolg M (2001) J Chem Phys 115:7348-7355

37. Cao XY, Dolg M (2002) J Mol Struct Theochem 581:139-147

38. Krishnan R, Binkley JS, Seeger R, Pople JA (1980) J Chem Phys 72:650-654

39. Blaudeau JP, McGrath MP, Curtiss LA, Radom L (1997) J Chem Phys 107:5016-5021

40. Clark T, Chandrasekhar J, Spitznagel GW, Schleyer PV (1983) J Comput Chem 4:294-301

41. Gaussian 03 Revision C02; Frisch MJ et al (2004) See Supporting Information for full citation

42. Michelini MD, Marcalo J, Russo N, Gibson JK (2010) Inorg Chem 49(8):3836-3850

43. Reed AE, Weinstock RB, Weinhold F (1985) J Chem Phys 83:735-746

44. Bader RFW (1990) Atoms in molecules. A quantum theory. Oxford University Press, Oxford

45. Varetto U Molekel 4.3 ed. Manno, Switzerland

46. Cheng P, Koyanagi GK, Bohme DK (2006) Chem Phys Chem 7:1813-1819

47. Cheng P, Koyanagi GK, Bohme DK (2007) J Phys Chem A 111:8561-8573

48. Milburn RK, Baranov VI, Hopkinson AC, Bohme DK (1998) J Phys Chem A 102:9803-9810

49. Shoeib T, Milburn RK, Koyanagi GK, Lavrov VV, Bohme DK, Siu KWM, Hopkinson AC (2000) Int J Mass Spectrom 201:87-100

50. Anbalagan V, Chien W, Gresham GL, Groenewold GS, Van Stipdonk MJ (2004) Rapid Commun Mass Spectrom 18:3028-3034

51. Irikura KK (1999) J Am Chem Soc 121:7689-7695 